\title{
Approach to shape factor determination in estimating horizontal wells productivity for pressure transient model of Mutalik et al.
}

\author{
Firas A. A. Al-Kabbawi ${ }^{1}$ (D)
}

Received: 29 July 2021 / Accepted: 15 October 2021 / Published online: 30 October 2021

(c) The Author(s) 2021

\begin{abstract}
Horizontal well productivity $\left(J_{\mathrm{h}}\right)$ equation at pseudo-steady state (PSS) of Mutalik et al. (in: Presented at SPE 63rd annual technical conference and exhibition, Houston, Texas, 1988) has long and widely been known to estimate well performance. One key parameter of that equation is the so-called shape factor $\left(C_{A}\right)$ that characterizes the effect of the pressure transient behavior at PSS depending on well and reservoir configuration. For limited well and reservoir configurations, $C_{A}$ tables had been generated decades ago, but at unknown accuracy they are still used widely via tedious correlation or interpolation from those reported $C_{A}$ tables to estimate $J_{\mathrm{h}}$ for different configurations even today. The innovation points in this study are as follows: (1) The pressure transient model of Mutalik et al. (in: Presented at SPE 63rd annual technical conference and exhibition, Houston, Texas, 1988) (PTM) is improved to generalized pressure transient model (GPTM) and verified by converting several dimensional parameters to dimensionless forms. (2) An efficient algorithm is developed, and accurate $C_{A}$ and $J_{\mathrm{h}}$ are obtained for any well and reservoir configuration. (3) The accuracy of the reported $C_{A}$ tables is quantified, and the consequences are determined when they are used to estimate $J_{\mathrm{h}}$. (4) New $C_{A}$ tables and their correspondence dimensionless time based on drainage area at PSS $\left(\left(T_{\mathrm{DA}}\right)_{\mathrm{PSS}}\right)$ tables are generated for a wider range of well and reservoir configurations. Although horizontal wells usually have been drilled with high dimensionless well length $\left(L_{\mathrm{D}}\right)$ industrially (i.e., $\left.L_{\mathrm{D}}>10\right)$, it is still a significant error in $J_{\mathrm{h}}$ by $(<7 \%)$ that has been determined when using the reported $\mathrm{C}_{\mathrm{A}}$ of PTM for rectangular reservoir aspect ratio $\left(x_{e} / y_{e}\right)=(1)$ and (2) in the both assumed input data, while for $\left(x_{e} / y_{e}=5\right)$, significant error in $J_{\mathrm{h}}$ starts from $(46.43 \%)$ to $(1037 \%)$ for $L_{\mathrm{D}}=(10)$ to $(100)$, respectively, in the first assumed input data [variable, dimensionless wellbore radius $\left.\left(r_{\mathrm{WD}}\right)\right]$ and expected the same in the second assumed input data (constant $\left.r_{\mathrm{WD}}\right)$.
\end{abstract}

Keywords Horizontal well productivity $\cdot$ Shape factor $\cdot$ Pressure transient model $\cdot$ Rectangular bounded reservoir . Instantaneous source functions

\section{Introduction}

$J_{\mathrm{h}}$ equation of Mutalik et al. (1988) is well known and presented by many authors (Duda et al. (1991), Economides et al. (1991b), Economides et al. (1991a), Frick and Economides (1993), Thomas et al. (1998), Penmatcha et al. (1999), Saavedra and Joshi (2002), Cho (2003), Jackson et al. (2011), Adesina et al. (2011), Ouyang (2015), Cetkovic et al. (2016), Wu et al. (2018), Luo et al. (2018), and Zhang et al. (2020)). In reservoir simulators, $J_{\mathrm{h}}$ equation of Mutalik et al. (1988) has been used to compute well productivity

Firas A. A. Al-Kabbawi

fi_im2005@yahoo.com

1 Iraqi Ministry of Oil, Baghdad, Iraq index (Krawchuk et al. 2006; Pinzon et al. 2007; Huebsch et al. 2008; Haidar et al. 2008; Brown and Tiwari 2010; Wood et al. 2010; and Leone et al. 2015). The $J_{\mathrm{h}}$ equation is defined as follows:

$$
\begin{aligned}
J_{\mathrm{h}} & =\frac{0.007078 k h / \mu_{o} B_{o}}{\ln \left(\frac{\sqrt{A / \pi}}{r_{\mathrm{w}}}\right)-2.1243-\ln \left(L / 4 r_{\mathrm{w}}\right)+\ln \sqrt{30.8828 / C_{A}}} \\
C_{A} & =\frac{8.9832 x_{e} y_{e}}{L^{2}} \exp \left[2\left(2 \pi\left(T_{\mathrm{DA}}\right)_{\mathrm{PSS}}-\left(P_{\mathrm{D}} T\right)_{\mathrm{PSS}}\right)\right]
\end{aligned}
$$

where $J_{\mathrm{h}}$ is the horizontal well productivity (STB/day.psi), $k$ is the reservoir permeability (md), $h$ is the reservoir thickness (ft), $\mu_{\mathrm{o}}$ is the oil viscosity (cp), $B_{\mathrm{o}}$ is the oil formation volume factor (bbl/STB), $A$ is the drainage area $\left(\mathrm{ft}^{2}\right), r_{\mathrm{w}}$ is the well radius ( $\mathrm{ft}$ ), $L$ is the length of horizontal well (ft), $x_{e}$

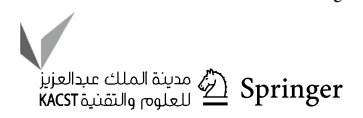


is the reservoir length in the $X$-direction (ft), the horizontal well is placed along the $X$-direction, $y_{e}$ is the reservoir length in the $Y$-direction ( $\mathrm{ft})$, and $\left(P_{\mathrm{D}} T\right)_{\mathrm{PSS}}$ is the total dimensionless pressure at PSS.

The $J_{\mathrm{h}}$ equation [Eq. (1)] is for rectangular bounded reservoir at depletion stage (i.e., PSS). In $\mathrm{C}_{\mathrm{A}}$ equation [i.e., Eq. (2)], the $\left(\mathrm{P}_{\mathrm{D}} \mathrm{T}\right)_{\mathrm{PSS}}$ was obtained by the PTM: (i.e., $r_{\mathrm{w}}=0.225 \mathrm{ft}$ and $y_{e}=933.33 \mathrm{ft}$ ) produces variable $r_{\mathrm{WD}}$ where $\left(r_{\mathrm{WD}}=2 r_{\mathrm{w}} / L\right)$ depends on penetration ratio (PR) and $\left(x_{e} / y_{e}\right)$. The second assumption of the input data shows that $r_{\mathrm{wD}}$ is constant and is equal to $\left(10^{-4}\right)$ for any well and reservoir configurations. These three limitations cast a doubt on the representativeness and usefulness of the reported $C_{A}$ tables for their respective configurations or other configurations for

$$
\begin{aligned}
& P_{\mathrm{D}} T=2 \pi \int_{0}^{T_{\mathrm{DA}}}\left\{\left[1+\frac{8 x_{e}}{\pi L} \sum_{n=1}^{\infty} \frac{1}{n} \exp \left(\frac{-n^{2} \pi^{2} y_{e} T_{\mathrm{DA}}}{x_{e}}\right) \cos \left(\frac{n \pi L x_{\mathrm{wD}}}{4 x_{e}}\right)\right.\right. \\
& \left.\cos \left(\frac{n \pi L\left(x_{\mathrm{wD}}+x_{D}\right)}{4 x_{e}}\right) \sin \left(\frac{n \pi L}{4 x_{e}}\right)\right] \times\left[1+2 \sum_{n=1}^{\infty} \exp \left(\frac{-n^{2} \pi^{2} x_{e} T_{\mathrm{DA}}}{y_{e}}\right)\right. \\
& \left.\cos \left(\frac{n \pi L y_{\mathrm{wD}}}{4 y_{e}}\right) \cos \left(\frac{n \pi L\left(y_{\mathrm{wD}}+y_{D}\right)}{4 y_{e}}\right)\right] \times[1+2 \\
& \left.\left.\sum_{n=1}^{\infty} \exp \left(-4 n^{2} \pi^{2} \frac{x_{e} y_{e}}{h^{2}} T_{\mathrm{DA}}\right) \cos \left(n \pi z_{\mathrm{wD}}\right) \cos \left(n \pi z_{\mathrm{D}}\right)\right]\right\} \mathrm{d} T_{\mathrm{DA}}
\end{aligned}
$$

where $P_{\mathrm{D}} T$ is the total dimensionless pressure, $T_{\mathrm{DA}}$ is the dimensionless time based on drainage area, $x_{\mathrm{wD}}, y_{\mathrm{wD}}$, and $z_{\mathrm{wD}}$ are the dimensionless well location coordinates, $x_{\mathrm{D}}$ is the $X$-coordinate for a point in the porous media. $\left(x_{\mathrm{D}}=0\right)$ at the horizontal well center, and $\left(x_{\mathrm{D}}=1\right.$ and -1$)$ at the well tips. $y \mathrm{D}$ is the $Y$-coordinate for a point in the porous media. $\left(y_{\mathrm{D}}=r_{\mathrm{WD}}\right)$ if the point is at the well wall, $z_{\mathrm{D}}$ is the $Z$-coordinate for a point in the porous media. $\left(z_{\mathrm{D}}=z_{\mathrm{WD}}\right)$ if the point is at the well wall

PTM [i.e., Eq. (3)] is based on 3D instantaneous source functions with Newman product method under homogenous and isotropic rectangular bounded reservoir at constant well flow rate and uniform flux wellbore condition of Gringarten and Ramey (1973). It is assumed that horizontal well is analogous to a vertical well of a vertical fracture. The equivalent infinite conductivity wellbore condition was obtained by solving $P_{\mathrm{D}} T$ at $x_{\mathrm{D}}$ equal to (0.732) (Mutalik et al. (1988) and Gringarten et al. (1974)). "Appendix 1" presents a summary of PTM.

When $P_{\mathrm{D}} T$ slope with time becomes constant at PSS and is equal to $(2 \pi)$, both the $\left(T_{\mathrm{DA}}\right)_{\mathrm{PSS}}$ and $\left(P_{\mathrm{D}} T\right)_{\mathrm{PSS}}$ have been obtained to use for $C_{A}$ calculation. $C_{A}$ at PSS also becomes constant for a given well and reservoir configuration.

PTM and their reported $C_{A}$ tables have identified three issues. Firstly, PTM as defined in Eq. (3) contains several dimensional parameters (i.e., $x_{e}, y_{e}, h$, and $L$ ) and this makes the solution not only awkward, but also difficult to use PTM to expand the reported $C_{A}$ tables to any other well and reservoir configurations. Secondly, PTM has not been verified in terms of $P_{\mathrm{D}} T$ which may lead to errors in the reported $C_{A}$ tables. The third issue is the discrepancy in the assumed input data of the reported $C_{A}$ tables. The first assumption of the input data which simply interpolation or extrapolation of those tables is required as the correlative models previously presented by Bahadori (2012), Bahadori et al. (2013), and Ahmadi et al. (2015).

The main purposes of this study are in four parts. (1) To overcome the first weakness in PTM (i.e., the dimensional parameters) by recasting PTM into a fully dimensionless form (i.e., GPTM) and to verify GPTM in terms of $P_{\mathrm{D}} T$. (2) To develop efficient algorithm to compute $C_{A}$ and $J_{\mathrm{h}}$ accurately for any well and reservoir configuration. Because $C_{A}$ depends on the all-configuration parameters, unlimited tables of $C_{A}$ can be generated; therefore, the MATLAB code is provided. (3) To quantify the accuracy of the reported $C_{A}$ tables in their both assumed input data (i.e., constant and variable $r_{\mathrm{WD}}$ ), and to determine the consequences of any identified errors in the reported $C_{A}$ tables when they are used to estimate $J_{\mathrm{h}}$. (4) To generate new $C_{A}$ tables for a wider spectrum of well and reservoir configurations.

\section{The generalized pressure transient model (GPTM)}

The PTM is improved to fully dimensionless form (i.e., to GPTM) by applying the following dimensionless parameters into Eq. (3):

$$
\begin{aligned}
& L_{\mathrm{D}}=\frac{L}{2 h} \\
& x_{e \mathrm{D}}=\frac{2 x_{e}}{L}
\end{aligned}
$$


$y_{e \mathrm{D}}=\frac{2 y_{e}}{L}$
Note that OCWL is used to indicate the offset of the well relative to the central well location (i.e., $\mathrm{OCWL}=1$ ) at a respective coordinate direction for the purpose of clas-

$$
\begin{aligned}
& P_{\mathrm{D}} T=2 \pi \int_{0}^{T_{\mathrm{DA}}}\left\{\left[1+\frac{4 x_{e \mathrm{D}}}{\pi} \sum_{n=1}^{\infty} \frac{1}{n} \exp \left(\frac{-n^{2} \pi^{2} y_{e \mathrm{D}} T_{D A}}{x_{e \mathrm{D}}}\right) \cos \left(\frac{n \pi x_{\mathrm{wD}}}{2 x_{e \mathrm{D}}}\right)\right.\right. \\
& \left.\cos \left(\frac{n \pi\left(x_{\mathrm{wD}}+x_{\mathrm{D}}\right)}{2 x_{e \mathrm{D}}}\right) \sin \left(\frac{n \pi x_{\mathrm{wD}}}{2 x_{e \mathrm{D}}}\right)\right] \times\left[1+2 \sum_{n=1}^{\infty} \exp \left(\frac{-n^{2} \pi^{2} x_{e \mathrm{D}} T_{\mathrm{DA}}}{y_{e \mathrm{D}}}\right)\right. \\
& \left.\cos \left(\frac{n \pi y_{\mathrm{wD}}}{2 y_{e \mathrm{D}}}\right) \cos \left(\frac{n \pi\left(y_{\mathrm{wD}}+y_{\mathrm{D}}\right)}{2 y_{e \mathrm{D}}}\right)\right] \times[1+2 \\
& \left.\left.\sum_{n=1}^{\infty} \exp \left(-4 n^{2} \pi^{2} x_{e \mathrm{D}} y_{e \mathrm{D}} L_{\mathrm{D}}^{2} T_{\mathrm{DA}}\right) \cos \left(n \pi z_{\mathrm{wD}}\right) \cos \left(n \pi z_{\mathrm{D}}\right)\right]\right\} \mathrm{d} T_{\mathrm{DA}}
\end{aligned}
$$

where $x_{e \mathrm{D}}$ is the dimensionless reservoir length in the $X$-direction and $y_{e \mathrm{D}}$ is the dimensionless reservoir length in the $Y$-direction

For anisotropic reservoir solution, the dimensionless parameters are presented in "Appendix 2."

The following meaningful mathematical relationship should be noted in the well and reservoir configuration:

$\frac{y_{\mathrm{wD}}}{y_{e \mathrm{D}}}=\frac{y_{\mathrm{w}}}{y_{e}}$ Used for centrally and off-centrally well location (OCWL) in the $Y$-direction.

$\frac{x_{\mathrm{wD}}}{x_{e \mathrm{D}}}=\frac{x_{\mathrm{w}}}{x_{e}}$ Used for centrally and OCWL in the $X$-direction.

$z_{\mathrm{wD}}=\frac{z_{\mathrm{w}}}{h}$ Used for centrally and OCWL in the $Z$-direction.

$\frac{x_{e \mathrm{D}}}{y_{e \mathrm{D}}}=\frac{x_{e}}{y_{e}}$ Dimensionless rectangular reservoir aspect ratio.

$\mathrm{PR}=\frac{L}{2 x_{e}} \mathrm{PR}$ is also equal to $\left(1 / x_{e \mathrm{D}}\right)$ [i.e., the inverse of Eq. (5)]. sifying the configurations only.

The efficient algorithm to solve Eq. (7) is developed and implemented in MATLAB code and is given in "Appendix 3."

$\mathrm{P}_{\mathrm{D}} \mathrm{T}$ by GPTM of this study [i.e., Eq. (7)] is verified against its counterpart by the horizontal well pressure transient model of Ozkan and Raghavan (1988) for a square bounded reservoir (i.e., $x_{e} / y_{e}=1$ ). $L_{\mathrm{D}}$ is equal to (10), and $\mathrm{PR}=(0.2)$ and (1), for a well that is centered in $x$-, $y$-, and $z$-directions [i.e., $\left(x_{\mathrm{wD}} / x_{e \mathrm{D}}=1\right),\left(y_{\mathrm{wD}} / y_{e \mathrm{D}}=1\right)$, and $\left(z_{\mathrm{wD}}=0.5\right)$, or $(\mathrm{OCWL}=1)]$. The wellbore condition is uniform flux $\left(x_{\mathrm{D}}=0\right)$, and $r_{\mathrm{wD}}$ is equal to $\left(2 \times 10^{-4}\right)$. Figure 1 shows the identical results of $P_{\mathrm{D}} T$ by both the models.

For further verification on GPTM, $P_{\mathrm{D}} T$ of this study is compared with $P_{\mathrm{D}} T$ of the pressure transient model of Gringarten et al. (1974) for vertical fracture well under square bounded reservoir. $\left(L_{\mathrm{D}}=10^{3}\right)$ (i.e., to make the thickness of the fracture to be zero), $\mathrm{PR}=(0.5)$ and $(1),(\mathrm{OCWL}=1)$,
Fig. 1 Comparison of $P_{\mathrm{D}} T$ by GPTM and by the pressure transient model of Ozkan and Raghavan (1988) for a centrally well located in a square reservoir

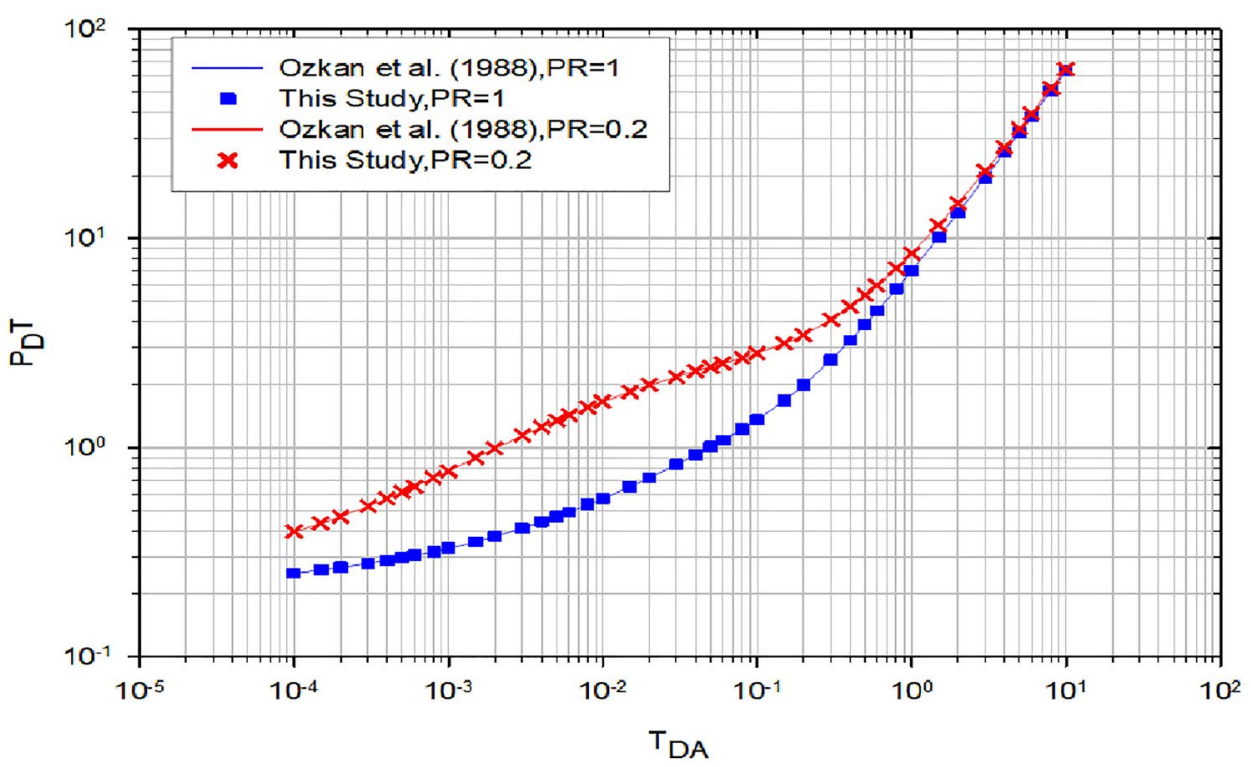

TDA 
Fig. 2 Comparison of $P_{\mathrm{D}} T$ by GPTM and by the pressure transient model of Gringarten et al. (1974) for vertical fracture well under square reservoir

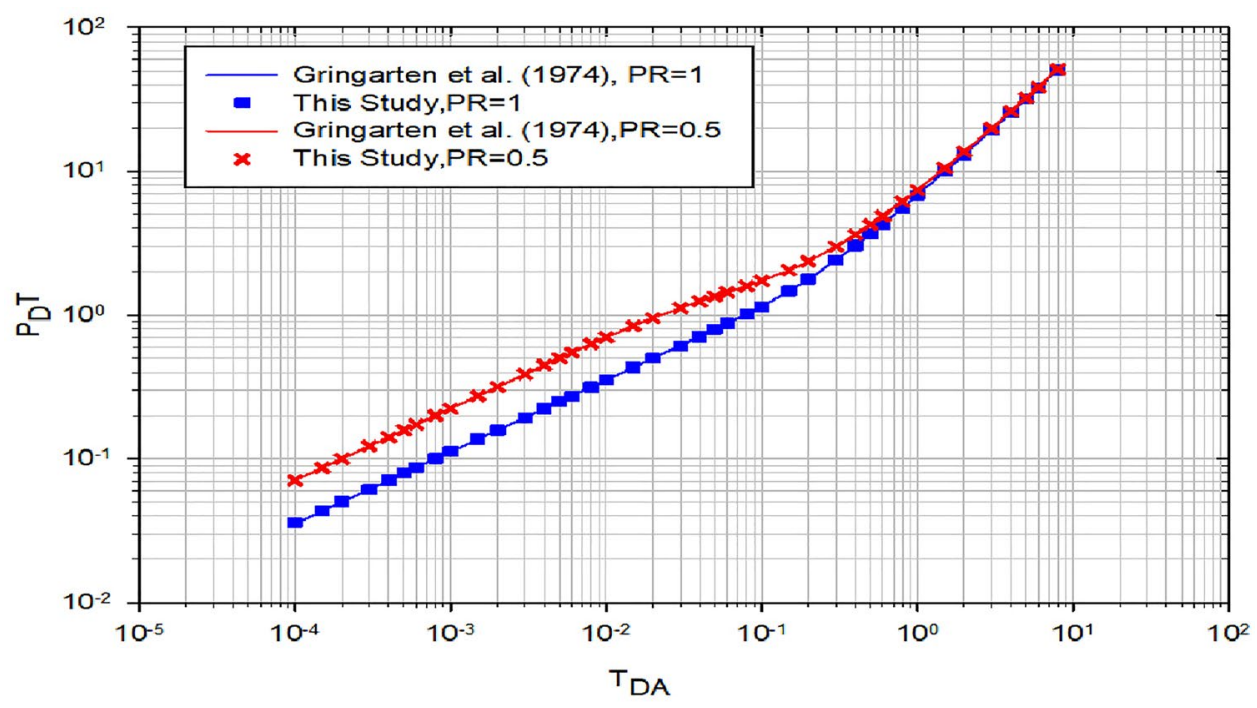

$\left(x_{\mathrm{D}}=0\right)$, and $\left(r_{\mathrm{wD}}=10^{-4}\right)$. Figure 2 shows the identical results of $P_{\mathrm{D}} T$ by both the models.

In the both previous verifications, the time intervals of $\mathrm{T}_{\mathrm{DA}}$ in Eq. (7) are to be taken: $\left(0-10^{-9}\right),\left(10^{-9}-10^{-8}\right)$, $\left(10^{-8}-10^{-7}\right),\left(10^{-7}-10^{-6}\right),\left(10^{-6}-10^{-5}\right),\left(10^{-5}-10^{-4}\right)$, $\left(10^{-4}-10^{-3}\right),\left(10^{-3}-10^{-2}\right),\left(10^{-2}-10^{-1}\right),\left(10^{-1}-1\right),(1-10)$, and (10-100), and within each of these intervals its $\mathrm{T}_{\mathrm{DA}}$ increment is taken to be $\left(10^{-9}\right),\left(10^{-9}\right),\left(10^{-9}\right),\left(10^{-9}\right),\left(10^{-9}\right)$, $\left(10^{-8}\right),\left(10^{-7}\right),\left(10^{-6}\right),\left(10^{-5}\right),\left(10^{-4}\right),\left(10^{-3}\right)$, and $\left(10^{-2}\right)$, respectively. These $T_{\mathrm{DA}}$ intervals and their increments are sufficient to yield accurate $P_{\mathrm{D}} T$. It is found that the first-time logarithmic cycle (FTLC) [i.e., $\left(0-10^{-9}\right)$ ] plays a crucially important role in determining the accuracy of $P_{\mathrm{D}} T$ at any period even at PSS and then in $C_{A}$ calculation as to be shown in the next sections.

The $C_{\mathrm{A}}$ equation [i.e., Eq. (2)] can be written in general form by substituting Eqs. (5) and (6) into Eq. (2):

$C_{A}=2.2458 x_{e \mathrm{D}} y_{e \mathrm{D}} \exp \left[2\left(2 \pi\left(T_{\mathrm{DA}}\right)_{\mathrm{PSS}}-\left(P_{\mathrm{D}} T\right)_{\mathrm{PSS}}\right)\right]$

For vertical fracture well (i.e., when $\left(L_{\mathrm{D}}>10^{3}\right)$ ), a comparison between the $C_{A}(s)$ by this study and their counterparts by Earlougher (1977) and Hagoort (2009) is presented in Table 1. For FTLC equal to $\left(0-10^{-9}\right)$ or $\left(0-10^{-5}\right)$, excellent matching is found with $C_{A}(s)$ by Hagoort (2009) at any PR and with $C_{A}(s)$ by Earlougher (1977) at just high PR.

In what follows, the reported $C_{A}$ tables by PTM for selected well and reservoir configurations are examined, and their well and reservoir configurations can be classified into four cases in terms of OCWL. Table 2 lists the four cases of the reported $\mathrm{C}_{\mathrm{A}}$ tables. The parameters in Cases (1) to (3) correspond to tables (4), (7), and (8) in Mutalik et al. (1988) paper, respectively. Note that parameters in Case (4) are deduced from Fig. 12 in Mutalik et al. (1988) paper.

\section{The accuracy of the reported $C_{A}$ tables by PTM (case 1)}

Although the accuracy of the reported $C_{A}$ tables by PTM for other cases has been examined, here only the results for the Case 1 are presented for both assumed input data (i.e., the discrepancy issue). For each $C_{A}$ by PTM, the counterpart $C_{A}$
Table 1 Comparison of $\mathrm{C}_{\mathrm{A}}$ by this study, Earlougher (1977) and Hagoort (2009)

\begin{tabular}{|c|c|c|c|c|c|c|}
\hline \multirow[t]{3}{*}{ PR } & \multicolumn{3}{|l|}{$C_{A}\left(X_{\mathrm{D}}=0.732\right)$} & \multicolumn{3}{|c|}{$C_{A}\left(X_{\mathrm{D}}=0.740098\right)$} \\
\hline & \multirow[t]{2}{*}{ Earlougher (1977) } & \multicolumn{2}{|c|}{ FTLC of this study } & \multirow[t]{2}{*}{ Hagoort (2009) } & \multicolumn{2}{|c|}{ FTLC of this study } \\
\hline & & $10^{-5}$ & $10^{-9}$ & & $10^{-5}$ & $10^{-9}$ \\
\hline 1 & 0.7887 & 0.788619 & 0.788344 & 0.7881 & 0.788619 & 0.788344 \\
\hline 0.7 & 1.3127 & 1.309808 & 1.309011 & 1.2733 & 1.322587 & 1.321782 \\
\hline 0.5 & 1.6620 & 1.589124 & 1.587596 & 1.5680 & 1.609405 & 1.607857 \\
\hline 0.3 & 1.9986 & 1.789103 & 1.785893 & 1.7895 & 1.815019 & 1.811763 \\
\hline 0.2 & 2.0348 & 1.855014 & 1.849753 & 1.8625 & 1.882811 & 1.877470 \\
\hline 0.1 & 2.6541 & 1.899797 & 1.888444 & 1.9068 & 1.928817 & 1.917290 \\
\hline
\end{tabular}


Table 2 The four cases of the reported $C_{A}$ tables by Mutalik et al. (1988)

\begin{tabular}{lllll}
\hline The parameters & $\begin{array}{l}\text { Case 1 } \\
\text { Central }\end{array}$ & $\begin{array}{l}\text { Case 2 } \\
Y_{w} / Y_{e}\end{array}$ & $\begin{array}{l}\text { Case 3 } \\
X_{\mathrm{w}} / X_{e}\end{array}$ & $\begin{array}{l}\text { Case 4 } \\
Z_{w} / h\end{array}$ \\
\hline OCWL & 1 & $0.25,0.5,1.0$ & $0.5,0.75,1.0$ & $0.1,0.2,0.3,0.4,0.5$ \\
$x_{e} / y_{e}$ & $1,2,5$ & $1,2,5$ & $1,2,5$ & 1 \\
$\mathrm{PR}$ & $0.2,0.4,0.6,0.8,1.0$ & $0.1,0.3,0.5,0.7,1.0$ & 0.5 & Not mentioned \\
$L_{\mathrm{D}}$ & $1,5,10,20,50,100$ & 100 & $1,2,5,10,100$ & 5 \\
$r_{\mathrm{WD}}$ & \multicolumn{2}{l}{ Depends on the assumed input data (the discrepancy issue) } \\
\hline
\end{tabular}

is calculated by GPTM. The relative errors of the reported $C_{A}$ tables are determined [i.e., $C_{A} \% \operatorname{Err}=\left(\left(\left(C_{A}\right)_{\mathrm{PTM}}-\left(C_{A}\right)_{\mathrm{GPTM}}\right) /\right.$ $\left.\left.\left(\left(C_{A}\right)_{\mathrm{GPTM}}\right) \times 100\right)\right]$ for the both assumed input data.

Tables 3 and 4 show the relative errors in the reported $C_{A}$ tables by PTM for the variable $r_{\mathrm{wD}}$ and the constant $r_{\mathrm{wD}}$, respectively. For the first assumed input data (variable $r_{\mathrm{wD}}$ ), Table 3 shows that in $x_{e} / y_{e}=(1)$ and (2), the $C_{A}$ errors of any $\mathrm{PR}$ are in reverse order with $\mathrm{L}_{\mathrm{D}}$, while in $x_{e} / y_{e}=(5)$, they are in non-order with $L_{\mathrm{D}}$. The maximum $C_{A}$ error is $(50 \%)$ at $(\mathrm{PR}=1),\left(L_{\mathrm{D}}=1\right)$, and $\left(x_{e} / y_{e}=2\right)$. For the second assumed input data (constant $r_{\mathrm{wD}}=10^{-4}$ ), Table 4 shows that in $x_{e} / y_{e}=(1)$ and (2), the $C_{A}$ errors of any PR are in reverse order with $L_{\mathrm{D}}$, while in $x_{e} / y_{e}=(5)$, they are in non-order with $L_{\mathrm{D}}$. The maximum $C_{A}$ error is $(1215 \%)$ at $(\mathrm{PR}=0.2)$, $\left(L_{\mathrm{D}}=1\right)$, and $\left(x_{e} / y_{e}=1\right)$. For any assumed input data, $\left(T_{\text {DA }}\right)_{\text {PSS }}$ by GPTM is noticeably close to its counterpart by PTM and both are independent of $L_{\mathrm{D}}$.

The errors in the reported $C_{A}$ tables are also found in the cases of off-center well location in $x$ - and $y$-directions for both assumed input data but are not reported here.

To determine the consequences of the identified errors in the reported $C_{A}$ tables of Mutalik et al. (1988) when they are used to estimate $J_{\mathrm{h}}$, an example problem is applied. The reservoir of $\left(y_{e}=933.33 \mathrm{ft}\right)$ and $\left(r_{\mathrm{w}}=0.225 \mathrm{ft}\right)$ is for the first assumed input data, and the reservoir of $\left(y_{e}=2640 \mathrm{ft}\right)$ and $\left(r_{\mathrm{wD}}=10^{-4}\right)$ is for the second assumed input data, and all are at $(k=1 \mathrm{md}),\left(\mu_{\mathrm{o}}=0.5 \mathrm{cp}\right)$, and $\left(B_{\mathrm{o}}=1.2 \mathrm{rbbl} / \mathrm{STB}\right)$. The $J_{\mathrm{h}}$ is calculated by using Eq. (1), and the $C_{A}(s)$ by PTM and GPTM is applied by using Tables 3 and 4 . For the first assumed input data, $\mathrm{PR}=(0.4),(1)$, and (0.8) for $x_{e} / y_{e}=(1)$, (2), and (5), respectively. For the second assumed input data, $\mathrm{PR}=(0.2)$ and (0.8) for $\left(x_{e} / y_{e}=1\right)$, and for $x_{e} / y_{e}=(2)$ and (5) they are not reported here. $(\mathrm{OCWL}=1)$ and $L_{\mathrm{D}}$ is from $(1)$ to (100). Figures 3 and 4 show a comparison of those $J_{\mathrm{h}}(s)$ and $C_{A}(s)$ for the both assumed input data, respectively.

Figure 3 shows that the reported $C_{A}$ tables of PTM lead to underestimation in the $J_{\mathrm{h}}$ for $x_{e} / y_{e}=(1)$ and (2) and lead to overestimation in the $J_{\mathrm{h}}$ for $x_{e} / y_{e}=(5)$. The relative error in the $J_{\mathrm{h}}$ for each selected $x_{e} / y_{e}=(1),(2)$, and (5) follows the same trend as those in $C_{A}$ table. The maximum underestimation in $J_{\mathrm{h}}$ is $(8.29 \%)$ corresponding to the error in $C_{A}$ at $\left(x_{e} / y_{e}=1\right)$ and $\left(L_{\mathrm{D}}=1\right)$, while the maximum overestimation in $J_{\mathrm{h}}$ is $(1037 \%)$ corresponding to the error in $C_{A}$ at $\left(x_{e} / y_{e}=5\right)$ and $\left(L_{\mathrm{D}}=100\right)$. For both $x_{e} / y_{e}=(1)$ and (2), although the maximum error in $J_{\mathrm{h}}$ (i.e., underestimation) at $\left(L_{\mathrm{D}}=1\right)$, a rather unrealistic case in most real fields, from Fig. 3 the error in $J_{\mathrm{h}}$ can still reach $(6.38 \%)$ underestimation for even a realistic configuration of $L_{\mathrm{D}}$ equal to (10). For $\left(x_{e} / y_{e}=5\right)$, the error in $J_{\mathrm{h}}$ (i.e., overestimation) is much more significant and starts from $(46.43 \%)$ to $(1037 \%)$ overestimation for $L_{\mathrm{D}}=(10)$ to (100), respectively.

Figure 4 shows that the reported $C_{A}$ tables of PTM lead to overestimation in the $J_{\mathrm{h}}$ for both $\mathrm{PR}=(0.2)$ and $(0.8)$. The relative error in the $J_{\mathrm{h}}$ for each PR follows the same trend as those in $\mathrm{C}_{\mathrm{A}}$ table. The maximum overestimation in $J_{\mathrm{h}}$ is $(32 \%)$ corresponding to the error in $C_{A}$ at $\left(L_{\mathrm{D}}=1\right)$ and $(\mathrm{PR}=0.2)$. Although the maximum error in $J_{\mathrm{h}}$ (i.e., overestimation) is at $\left(L_{\mathrm{D}}=1\right)$, a rather unrealistic case in most real fields, from Fig. 4 the error in $J_{\mathrm{h}}$ can still reach $(7 \%)$ overestimation for even a realistic configuration of $L_{\mathrm{D}}$ equal to (10).

\section{The source of errors in the reported $C_{A}$ tables}

Given that both PTM and GPTM solutions are derived identically, except re-casting some variables into dimensionless forms in the latter model, the source of the errors in the reported $C_{A}$ tables may be originated from the evaluation of the $\mathrm{P}_{\mathrm{D}} \mathrm{T}$ which was not verified by Mutalik et al. (1988).

Figure 5 shows the effect of using FTLC $=\left(0-10^{-9}\right)$ and $\left(0-10^{-5}\right)$ on the $C_{A}$ accuracy. GPTM is used to calculate $C_{A}$ for square reservoir, $\left(r_{\mathrm{WD}}=10^{-4}\right),(\mathrm{OCWL}=1), \mathrm{PR}=(0.1)$, (0.5), and (1), and $L_{\mathrm{D}}$ from (1) to $\left(10^{3}\right)$. The maximum error in $C_{A}$ is $(3630 \%)$ which appears at the lowest PR (i.e., $\mathrm{PR}=0.1$ ) and $L_{\mathrm{D}}$ (i.e., $\left.L_{\mathrm{D}}=1\right)$. Notice that the error in $\mathrm{C}_{\mathrm{A}}$ becomes small and not significant at $\left(L_{\mathrm{D}}>100\right)$ and suggests that the FTLC of $\left(0-10^{-5}\right)$ would be sufficient for $C_{A}$ accuracy when $\left(L_{\mathrm{D}}>100\right)$ for any well and reservoir configuration. This has also been shown previously in Table 1 for vertical fracture well case when $\left(L_{\mathrm{D}}>10^{3}\right)$.

The pressure drop that occurs at the very early time in the $P_{\mathrm{D}} T$ solution, especially when $\mathrm{L}_{\mathrm{D}}$ is small (i.e., when the reservoir thickness is large), has significant effects on the $C_{A}$ accuracy. The evaluation of $P_{\mathrm{D}} T$ in that period requires 
Table 3 Comparison between $C_{A}$ and $\left(T_{\mathrm{DA}}\right)_{\mathrm{PSS}}$ of this study and Mutalik et al. (1988) (when $r_{\mathrm{wD}}=0.225 \mathrm{ft}$ and $y_{e}=933.33 \mathrm{ft}$ ) (variable $r_{\mathrm{wD}}$ )

$\mathrm{PR}=0.2$, Central well, $x_{e \mathrm{D}} / y_{e \mathrm{D}}=1, r_{\mathrm{wD}}=0.0012054$

$L_{\mathrm{D}} \quad$ Mutalik et al. (1988) This study $\overline{C_{A} \quad\left(T_{\mathrm{DA}}\right)_{\mathrm{PSS}}} \quad \overline{C_{A} \quad\left(T_{\mathrm{DA}}\right)_{\mathrm{PSS}}}$

\begin{tabular}{|c|c|c|c|c|c|c|c|c|c|c|c|}
\hline \multirow[t]{2}{*}{$L_{\mathrm{D}}$} & \multicolumn{2}{|c|}{ Mutalik et al. (1988) } & \multicolumn{2}{|c|}{ This study } & \multirow[t]{2}{*}{$\mathrm{C}_{\mathrm{A}} \% \mathrm{Err}$} & \multirow[t]{2}{*}{$L_{\mathrm{D}}$} & \multicolumn{2}{|c|}{ Mutalik et al. (1988) } & \multicolumn{2}{|c|}{ This study } & \multirow[t]{2}{*}{$C_{A} \% \mathrm{Err}$} \\
\hline & $C_{A}$ & $\left(T_{\mathrm{DA}}\right)_{\mathrm{PSS}}$ & $C_{A}$ & $\left(T_{\mathrm{DA}}\right)_{\mathrm{PSS}}$ & & & $C_{A}$ & $\left(T_{\mathrm{DA}}\right)_{\mathrm{PSS}}$ & $C_{A}$ & $\left(T_{\mathrm{DA}}\right)_{\mathrm{PSS}}$ & \\
\hline 1 & 0.0163 & 0.4 & 0.0147 & 0.4075 & 10.8994 & 1 & 0.0043 & 0.4 & 0.0067 & 0.4025 & 36.28 \\
\hline 5 & 0.9813 & 0.4 & 0.9608 & 0.4075 & 2.1390 & 5 & 0.703 & 0.4 & 0.7678 & 0.4025 & 8.44 \\
\hline 10 & 1.4438 & 0.4 & 1.4286 & 0.4075 & 1.0640 & 10 & 1.1538 & 0.4 & 1.2235 & 0.4025 & 5.70 \\
\hline 20 & 1.6917 & 0.4 & 1.6827 & 0.4075 & 0.5349 & 20 & 1.4595 & 0.4 & 1.4920 & 0.4025 & 2.18 \\
\hline 50 & 1.8178 & 0.4 & 1.8138 & 0.4075 & 0.2205 & 50 & 1.6276 & 0.4 & 1.6419 & 0.4025 & 0.87 \\
\hline 100 & 1.834 & 0.4 & 1.8445 & 0.4075 & 0.5693 & 100 & 1.6738 & 0.4 & 1.6811 & 0.4025 & 0.44 \\
\hline
\end{tabular}

$\mathrm{PR}=0.6$, Central well, $x_{e \mathrm{D}} / y_{e \mathrm{D}}=1, r_{\mathrm{wD}}=0.000401787$

$L_{\mathrm{D}}$

Mutalik et al. (1988)

$C_{A} \quad\left(T_{\mathrm{DA}}\right)_{\mathrm{PSS}}$

1

$-0.6268$

$10 \quad 1.0241$

$20 \quad 1.2644$

$50 \quad 1.402$

$100 \quad 1.439$

\begin{tabular}{ll}
\multicolumn{2}{l}{ This study } \\
\hline$C_{A}$ & $\left(T_{\mathrm{DA}}\right)_{\mathrm{PSS}}$ \\
\hline 0.0039 & 0.3944 \\
0.6075 & 0.3944 \\
1.0082 & 0.3944 \\
1.2546 & 0.3944 \\
1.3975 & 0.3944 \\
1.4367 & 0.3944
\end{tabular}

$C_{A} \% \mathrm{Err}$

$\mathrm{PR}=0.8$, Central well, $x_{e \mathrm{D}} / y_{e \mathrm{D}}=1, r_{\mathrm{wD}}=0.00030134$

$\mathrm{PR}=0.4$, Central well, $x_{e \mathrm{D}} / y_{e \mathrm{D}}=1, r_{\mathrm{wD}}=0.0006026$

\begin{tabular}{lllllll}
\hline$L_{\mathrm{D}}$ & \multicolumn{2}{l}{ Mutalik et al. (1988) } & & \multicolumn{2}{l}{ This study } & \multirow{2}{*}{$C_{A} \%$ Err } \\
\cline { 2 - 3 } \cline { 5 - 6 } & $C_{A}$ & $\left(T_{\mathrm{DA}}\right)_{\mathrm{PSS}}$ & & $C_{A}$ & $\left(T_{\mathrm{DA}}\right)_{\mathrm{PSS}}$ & \\
\hline 1 & 0.002 & 0.4 & 0.0023 & 0.3911 & 12.10 \\
5 & 0.4406 & 0.4 & 0.4514 & 0.3911 & 2.38 \\
10 & 0.7616 & 0.4 & 0.7709 & 0.3911 & 1.21 \\
20 & 0.9673 & 0.4 & 0.9732 & 0.3911 & 0.60 \\
50 & 1.0909 & 0.4 & 1.0934 & 0.3911 & 0.23 \\
100 & 1.126 & 0.4 & 1.1273 & 0.3911 & 0.12
\end{tabular}

$\mathrm{PR}=1$, Central well, $x_{\mathrm{eD}} / y_{\mathrm{eD}}=1, r_{\mathrm{wD}}=0.000241072$

\begin{tabular}{|c|c|c|c|c|c|c|c|c|c|c|c|}
\hline \multirow[t]{2}{*}{$L_{\mathrm{D}}$} & \multicolumn{2}{|c|}{ Mutalik et al. (1988) } & \multicolumn{2}{|c|}{ This study } & \multirow[t]{2}{*}{$C_{A} \% \mathrm{Err}$} & \multirow[t]{2}{*}{$L_{\mathrm{D}}$} & \multicolumn{2}{|c|}{ Mutalik et al. (1988) } & \multicolumn{2}{|c|}{ This study } & \multirow[t]{2}{*}{$C_{A} \% \mathrm{Err}$} \\
\hline & $C_{A}$ & $\left(T_{\mathrm{DA}}\right)_{\mathrm{PSS}}$ & $C_{A}$ & $\left(T_{\mathrm{DA}}\right)_{\mathrm{PSS}}$ & & & $C_{A}$ & $\left(T_{\mathrm{DA}}\right)_{\mathrm{PSS}}$ & $C_{A}$ & $\left(T_{\mathrm{DA}}\right)_{\mathrm{PSS}}$ & \\
\hline 1 & 0.00085 & 0.4 & 0.0012 & 0.3924 & 28.79 & 1 & 0.0044 & 0.6 & 0.0054 & 0.7396 & 17.86 \\
\hline 5 & 0.2773 & 0.4 & 0.2968 & 0.3924 & 6.56 & 5 & 0.5869 & 0.6 & 0.6095 & 0.7396 & 3.71 \\
\hline 10 & 0.501 & 0.4 & 0.5183 & 0.3924 & 3.34 & 10 & 0.9531 & 0.6 & 0.9714 & 0.7396 & 1.88 \\
\hline 20 & 0.6506 & 0.4 & 0.6617 & 0.3924 & 1.67 & 20 & 1.1734 & 0.6 & 1.1845 & 0.7396 & 0.93 \\
\hline 50 & 0.7435 & 0.4 & 0.7485 & 0.3924 & 0.66 & 50 & 1.2986 & 0.6 & 1.3035 & 0.7396 & 0.37 \\
\hline 100 & 0.771 & 0.4 & 0.7734 & 0.3924 & 0.31 & 100 & 1.3322 & 0.6 & 1.3346 & 0.7396 & 0.18 \\
\hline \multicolumn{6}{|c|}{$\mathrm{PR}=0.4$, Central well, $x_{\mathrm{eD}} / y_{\mathrm{eD}}=2, r_{\mathrm{wD}}=0.00030134$} & \multicolumn{6}{|c|}{$\mathrm{PR}=0.6$, Central well, $x_{\mathrm{eD}} / y_{\mathrm{eD}}=2, r_{\mathrm{wD}}=0.000200894$} \\
\hline \multirow[t]{2}{*}{$L_{\mathrm{D}}$} & \multicolumn{2}{|c|}{ Mutalik et al. (1988) } & \multicolumn{2}{|c|}{ This study } & \multirow[t]{2}{*}{$C_{A} \% \mathrm{Err}$} & \multirow[t]{2}{*}{$L_{\mathrm{D}}$} & \multicolumn{2}{|c|}{ Mutalik et al. (1988) } & \multicolumn{2}{|c|}{ This study } & $C_{A} \%$ Err \\
\hline & $C_{A}$ & $\left(T_{\mathrm{DA}}\right)_{\mathrm{PSS}}$ & $C_{A}$ & $\left(T_{\mathrm{DA}}\right)_{\mathrm{PSS}}$ & & & $C_{A}$ & $\left(T_{\mathrm{DA}}\right)_{\mathrm{PSS}}$ & $C_{A}$ & $\left(T_{\mathrm{DA}}\right)_{\mathrm{PSS}}$ & \\
\hline 1 & 0.0033 & 0.6 & 0.0026 & 0.708 & 25.43 & 1 & 0.0013 & 0.6 & 0.0016 & 0.6296 & 18.82 \\
\hline 5 & 0.544 & 0.6 & 0.5212 & 0.708 & 4.37 & 5 & 0.423 & 0.6 & 0.4388 & 0.6296 & 3.60 \\
\hline 10 & 0.9095 & 0.6 & 0.8902 & 0.708 & 2.17 & 10 & 0.7664 & 0.6 & 0.7805 & 0.6296 & 1.81 \\
\hline 20 & 1.1359 & 0.6 & 1.1238 & 0.708 & 1.08 & 20 & 0.9963 & 0.6 & 1.0055 & 0.6296 & 0.91 \\
\hline 50 & 1.2686 & 0.6 & 1.2627 & 0.708 & 0.47 & 50 & 1.1394 & 0.6 & 1.1436 & 0.6296 & 0.36 \\
\hline 100 & 1.3046 & 0.6 & 1.3018 & 0.708 & 0.22 & 100 & 1.1817 & 0.6 & 1.1838 & 0.6296 & 0.18 \\
\hline \multicolumn{6}{|c|}{$\mathrm{PR}=0.8$, Central well, $x_{\mathrm{eD}} / y_{\mathrm{eD}}=2, r_{\mathrm{wD}}=0.00015067$} & \multicolumn{6}{|c|}{$\mathrm{PR}=1$, Central well, $x_{\mathrm{eD}} / y_{\mathrm{eD}}=2, r_{\mathrm{wD}}=0.000120536$} \\
\hline \multirow[t]{2}{*}{$L_{\mathrm{D}}$} & \multicolumn{2}{|c|}{ Mutalik et al. (1988) } & \multicolumn{2}{|c|}{ This Study } & \multirow[t]{2}{*}{$C_{A} \%$ Err } & \multirow[t]{2}{*}{$L_{\mathrm{D}}$} & \multicolumn{2}{|c|}{ Mutalik et al. (1988) } & \multicolumn{2}{|c|}{ This study } & $C_{A} \% \mathrm{Err}$ \\
\hline & $C_{A}$ & $\left(T_{\mathrm{DA}}\right)_{\mathrm{PSS}}$ & $C_{A}$ & $\left(T_{\mathrm{DA}}\right)_{\mathrm{PSS}}$ & & & $C_{A}$ & $\left(T_{\mathrm{DA}}\right)_{\mathrm{PSS}}$ & $C_{A}$ & $\left(T_{\mathrm{DA}}\right)_{\mathrm{PSS}}$ & \\
\hline 1 & 0.00061 & 0.6 & 0.0010 & 0.6077 & 37.08 & 1 & 0.00025 & 0.2 & 0.0005 & 0.2138 & 50.19 \\
\hline 5 & 0.3051 & 0.6 & 0.3291 & 0.0724 & 7.30 & 5 & 0.19 & 0.2 & 0.2181 & 0.2046 & 12.87 \\
\hline 10 & 0.58525 & 0.6 & 0.6025 & 0.0724 & 2.86 & 10 & 0.381 & 0.2 & 0.4082 & 0.2046 & 6.66 \\
\hline 20 & 0.7825 & 0.6 & 0.7874 & 0.0724 & 0.62 & 20 & 0.5212 & 0.2 & 0.5395 & 0.2046 & 3.39 \\
\hline 50 & 0.9109 & 0.6 & 0.9033 & 0.0724 & 0.84 & 50 & 0.6145 & 0.2 & 0.6230 & 0.2046 & 1.37 \\
\hline 100 & 0.95 & 0.6 & 0.9378 & 0.0724 & 1.31 & 100 & 0.6438 & 0.2 & 0.6482 & 0.2046 & 0.69 \\
\hline
\end{tabular}


Table 3 (continued)

\begin{tabular}{|c|c|c|c|c|c|c|c|c|c|c|c|}
\hline \multicolumn{6}{|c|}{$\mathrm{PR}=0.2$, Central well, $x_{\mathrm{eD}} / y_{\mathrm{eD}}=5, r_{\mathrm{wD}}=0.000241072$} & \multicolumn{6}{|c|}{$\mathrm{PR}=0.4$, Central well, $x_{\mathrm{eD}} / y_{\mathrm{eD}}=5, r_{\mathrm{wD}}=0.000120536$} \\
\hline \multirow[t]{2}{*}{$L_{\mathrm{D}}$} & \multicolumn{2}{|c|}{ Mutalik et al. (1988) } & \multicolumn{2}{|c|}{ This study } & \multirow[t]{2}{*}{$C_{A} \%$ Err } & \multirow[t]{2}{*}{$L_{\mathrm{D}}$} & \multicolumn{2}{|c|}{ Mutalik et al. (1988) } & \multicolumn{2}{|c|}{ This study } & \multirow[t]{2}{*}{$C_{A} \% \mathrm{Err}$} \\
\hline & $C_{A}$ & $\left(T_{\mathrm{DA}}\right)_{\mathrm{PSS}}$ & $C_{A}$ & $\left(T_{\mathrm{DA}}\right)_{\mathrm{PSS}}$ & & & $C_{A}$ & $\left(T_{\mathrm{DA}}\right)_{\mathrm{PSS}}$ & $C_{A}$ & $\left(T_{\mathrm{DA}}\right)_{\mathrm{PSS}}$ & \\
\hline 1 & 0.0002 & 2 & 0.0003 & 2.029 & 39.65 & 1 & 0.0003 & 2 & 0.0003 & 1.957 & 0.82 \\
\hline 5 & 0.0859 & 2 & 0.0785 & 2.029 & 9.44 & 5 & 0.149 & 2 & 0.1251 & 1.957 & 19.13 \\
\hline 10 & 0.1606 & 2 & 0.1371 & 2.029 & 17.16 & 10 & 0.285 & 2 & 0.2341 & 1.957 & 21.73 \\
\hline 20 & 0.212 & 2 & 0.1750 & 2.029 & 21.15 & 20 & 0.3822 & 2 & 0.3094 & 1.957 & 23.53 \\
\hline 50 & 0.2442 & 2 & 0.1979 & 2.029 & 23.37 & 50 & 0.4446 & 2 & 0.3573 & 1.957 & 24.42 \\
\hline 100 & 0.2503 & 2 & 0.2045 & 2.029 & 22.38 & 100 & 0.4636 & 2 & 0.3718 & 1.957 & 24.69 \\
\hline \multicolumn{6}{|c|}{$\mathrm{PR}=0.6$, Central well, $x_{\mathrm{eD}} / y_{\mathrm{eD}}=5, r_{\mathrm{wD}}=0.00008035$} & \multicolumn{6}{|c|}{$\mathrm{PR}=0.8$, Central well, $x_{\mathrm{eD}} / y_{\mathrm{eD}}=5, r_{\mathrm{wD}}=0.000060268$} \\
\hline \multirow[t]{2}{*}{$L_{\mathrm{D}}$} & \multicolumn{2}{|c|}{ Mutalik et al. (1988) } & \multicolumn{2}{|c|}{ This study } & \multirow[t]{2}{*}{$C_{A} \%$ Err } & \multirow[t]{2}{*}{$L_{\mathrm{D}}$} & \multicolumn{2}{|c|}{ Mutalik et al. (1988) } & \multicolumn{2}{|c|}{ This study } & $C_{A} \% \mathrm{Err}$ \\
\hline & $C_{A}$ & $\left(T_{\mathrm{DA}}\right)_{\mathrm{PSS}}$ & $C_{A}$ & $\left(T_{\mathrm{DA}}\right)_{\mathrm{PSS}}$ & & & $C_{A}$ & $\left(T_{\mathrm{DA}}\right)_{\mathrm{PSS}}$ & $C_{A}$ & $\left(T_{\mathrm{DA}}\right)_{\mathrm{PSS}}$ & \\
\hline 1 & 0.00019 & 2 & 0.0003 & 1.75 & 34.71 & 1 & 0.0003 & 2 & 0.0002 & 1.7030 & 43.92 \\
\hline 5 & 0.1869 & 2 & 0.1701 & 1.75 & 9.89 & 5 & 0.2111 & 2 & 0.1617 & 1.7030 & 30.55 \\
\hline 10 & 0.3876 & 2 & 0.3315 & 1.75 & 16.91 & 10 & 0.4144 & 2 & 0.3244 & 1.7030 & 27.74 \\
\hline 20 & 0.5412 & 2 & 0.4471 & 1.75 & 21.05 & 20 & 0.5609 & 2 & 0.4439 & 1.7030 & 26.37 \\
\hline 50 & 0.645 & 2 & 0.5227 & 1.75 & 23.40 & 50 & 0.6571 & 2 & 0.5234 & 1.7030 & 25.55 \\
\hline 100 & 0.6782 & 2 & 0.5460 & 1.75 & 24.20 & 100 & 0.687 & 2 & 0.5483 & 1.7030 & 25.29 \\
\hline \multicolumn{6}{|c|}{$\mathrm{PR}=1$, Central well, $x_{\mathrm{eD}} / y_{\mathrm{eD}}=5, r_{w D}=0.0000482$} & & & & & & \\
\hline \multirow[t]{2}{*}{$L_{\mathrm{D}}$} & \multicolumn{2}{|c|}{ Mutalik et al. (1988) } & \multicolumn{2}{|c|}{ This study } & \multirow[t]{2}{*}{$\mathrm{C}_{\mathrm{A}} \% \mathrm{Err}$} & & & & & & \\
\hline & $C_{A}$ & $\left(T_{\mathrm{DA}}\right)_{\mathrm{PSS}}$ & $C_{A}$ & $\left(T_{\mathrm{DA}}\right)_{\mathrm{PSS}}$ & & & & & & & \\
\hline 1 & 0.00011 & 0.4 & 0.0001 & 0.4832 & 19.72 & & & & & & \\
\hline 5 & 0.1241 & 0.6 & 0.0994 & 0.0748 & 24.81 & & & & & & \\
\hline 10 & 0.2548 & 0.6 & 0.2040 & 0.0748 & 24.92 & & & & & & \\
\hline 20 & 0.3527 & 0.6 & 0.2822 & 0.0748 & 24.98 & & & & & & \\
\hline 50 & 0.4187 & 0.6 & 0.3350 & 0.0748 & 24.98 & & & & & & \\
\hline 100 & 0.4397 & 0.6 & 0.3518 & 0.0748 & 19.81 & & & & & & \\
\hline
\end{tabular}

to use a much shorter FTLC [i.e., FTLC $=\left(0-10^{-9}\right)$ ] to gain sufficient accuracy.

Due to the absence of the information about the selected FTLC in the calculation of the reported $C_{A}$ tables by PTM, $\mathrm{C}_{\mathrm{A}}$ tables have errors in reverse order with $L_{\mathrm{D}}$ as shown previously for $x_{e} / y_{e}=(1)$ and (2) in Tables 3 and 4. Therefore, the source of errors in the reported $\mathrm{C}_{\mathrm{A}}$ tables by PTM could be originated and justified from the using of long FTLC in the $P_{\mathrm{D}} T$ evaluation. About $\left(x_{e} / y_{e}=5\right)$, no analysis can be achieved.

\section{Additional characteristics of PTM and GPTM}

Figure 6 shows the effect of OCWL in the Z-direction on $C_{A}$ for square reservoir, $\left(r_{\mathrm{WD}}=10^{-4}\right)$ and $\mathrm{PR}$ is equal to $(0.1)$ and (0.9). The effect of $z_{\mathrm{wD}}$ (i.e., $z_{\mathrm{D}}=z_{\mathrm{wD}}$ ) on the $C_{A}$ that is calculated by GPTM becomes insignificant when $\left(L_{\mathrm{D}}>35\right)$ $\left(C_{A} \%\right.$ error $\left.<\% 5\right)$ which is inconsistent with their $\mathrm{C}_{\mathrm{A}}$ counterparts by PTM [i.e., Fig. 12 in Mutalik et al. (1988) paper] because $z_{\mathrm{wD}}$ will be insignificant when $\left(L_{\mathrm{D}}>5\right)$. Therefore, $z_{\mathrm{wD}}$ should be considered as a major parameter for any correlation.

Table 5 which is presented at the end of the paper shows the effect of the wellbore radius on $\mathrm{C}_{\mathrm{A}}$ for square reservoir and $\mathrm{PR}=(0.1)$ and (1). When $r_{\mathrm{wD}}$ increases two times (i.e., from $\left(5 \times 10^{-5}\right)$ to $\left.\left(10^{-4}\right)\right)$, a significant error occurs when $\left(L_{\mathrm{D}}<15\right)$, and when $r_{\mathrm{wD}}$ increases (10) to (20) times [i.e., from $\left(5 \times 10^{-4}\right)$ to $\left(10^{-3}\right)$ ], a significant error occurs when $\left(L_{\mathrm{D}}<50\right)$. This is also inconsistent with their $\mathrm{C}_{\mathrm{A}}$ counterparts by PTM (i.e., table (9) in Mutalik et al. (1988) paper), the significant error will occur when $\left(L_{\mathrm{D}}<3\right)$ if $r_{\mathrm{wD}}$ increases 10 times. Therefore, $r_{\mathrm{wD}}$ should be considered as a major parameter for any correlation. 
Table 4 Comparison between $C_{A}$ and $\left(\mathrm{T}_{\mathrm{DA}}\right)_{\mathrm{PSS}}$ of this study and Mutalik et al. (1988) (when constant $\mathrm{r}_{\mathrm{wD}}=10^{-4}$ )

\begin{tabular}{|c|c|c|c|c|c|c|c|c|c|c|c|}
\hline \multicolumn{6}{|c|}{$\mathrm{PR}=0.2$, Central well, $x_{\mathrm{eD}} / y_{\mathrm{eD}}=1, r_{\mathrm{wD}}=10^{-4}$} & \multicolumn{6}{|c|}{$\mathrm{PR}=0.4$, Central well, $x_{\mathrm{eD}} / y_{\mathrm{eD}}=1, r_{\mathrm{wD}}=10^{-4}$} \\
\hline \multirow[t]{2}{*}{$L_{\mathrm{D}}$} & \multicolumn{2}{|c|}{ Mutalik et al. (1988) } & \multicolumn{2}{|c|}{ This study } & \multirow[t]{2}{*}{$C_{A} \% \mathrm{Err}$} & \multirow[t]{2}{*}{$L_{\mathrm{D}}$} & \multicolumn{2}{|c|}{ Mutalik et al. (1988) } & \multicolumn{2}{|c|}{ This study } & \multirow[t]{2}{*}{$C_{A} \% \mathrm{Err}$} \\
\hline & $C_{A}$ & $\left(T_{\mathrm{DA}}\right)_{\mathrm{PSS}}$ & $C_{A}$ & $\left(T_{\mathrm{DA}}\right)_{\mathrm{PSS}}$ & & & $C_{A}$ & $\left(T_{\mathrm{DA}}\right)_{\mathrm{PSS}}$ & $C_{A}$ & $\left(T_{\mathrm{DA}}\right)_{\mathrm{PSS}}$ & \\
\hline 1 & 0.0163 & 0.4 & 0.0012 & 0.4075 & 1215.58 & 1 & 0.0043 & 0.4 & 0.0011 & 0.4025 & 284.27 \\
\hline 5 & 0.9813 & 0.4 & 0.5858 & 0.4075 & 67.50 & 5 & 0.703 & 0.4 & 0.5361 & 0.4025 & 31.14 \\
\hline 10 & 1.4438 & 0.4 & 1.1155 & 0.4075 & 29.43 & 10 & 1.1538 & 0.4 & 1.0224 & 0.4025 & 12.86 \\
\hline 20 & 1.6917 & 0.4 & 1.4869 & 0.4075 & 13.77 & 20 & 1.4595 & 0.4 & 1.3638 & 0.4025 & 7.02 \\
\hline 50 & 1.8178 & 0.4 & 1.7261 & 0.4075 & 5.31 & 50 & 1.6276 & 0.4 & 1.5839 & 0.4025 & 2.76 \\
\hline 100 & 1.834 & 0.4 & 1.7990 & 0.4075 & 1.95 & 100 & 1.6738 & 0.4 & 1.6511 & 0.4025 & 1.37 \\
\hline
\end{tabular}

$\mathrm{PR}=0.6$, Central well, $x_{\mathrm{eD}} / y_{\mathrm{eD}}=1, r_{\mathrm{wD}}=10^{-4}$

\begin{tabular}{|c|c|c|c|c|c|c|c|c|c|c|c|}
\hline \multirow[t]{2}{*}{$L_{\mathrm{D}}$} & \multicolumn{2}{|c|}{ Mutalik et al. (1988) } & \multicolumn{2}{|c|}{ This study } & \multirow[t]{2}{*}{$C_{A} \% \mathrm{Err}$} & \multirow[t]{2}{*}{$L_{\mathrm{D}}$} & \multicolumn{2}{|c|}{ Mutalik et al. (1988) } & \multicolumn{2}{|c|}{ This study } & \multirow[t]{2}{*}{$C_{A} \% \mathrm{Er}$} \\
\hline & $C_{A}$ & $\left(T_{\mathrm{DA}}\right)_{\mathrm{PSS}}$ & $C_{A}$ & $\left(T_{\mathrm{DA}}\right)_{\mathrm{PSS}}$ & & & $C_{A}$ & $\left(T_{\mathrm{DA}}\right)_{\mathrm{PSS}}$ & $C_{A}$ & $\left(T_{\mathrm{DA}}\right)_{\mathrm{PSS}}$ & \\
\hline 1 & 0.0034 & 0.4 & 0.0010 & 0.3944 & 253.80 & 1 & 0.002 & 0.4 & 0.0008 & 0.3911 & 164.90 \\
\hline 5 & 0.6268 & 0.4 & 0.4600 & 0.3944 & 36.26 & 5 & 0.4406 & 0.4 & 0.3620 & 0.3911 & 21.71 \\
\hline 10 & 1.0241 & 0.4 & 0.8773 & 0.3944 & 16.73 & 10 & 0.7616 & 0.4 & 0.6904 & 0.3911 & 10.32 \\
\hline 20 & 1.2644 & 0.4 & 1.1703 & 0.3944 & 8.04 & 20 & 0.9673 & 0.4 & 0.9209 & 0.3911 & 5.03 \\
\hline 50 & 1.402 & 0.4 & 1.3592 & 0.3944 & 3.15 & 50 & 1.0909 & 0.4 & 1.0696 & 0.3911 & 1.99 \\
\hline 100 & 1.439 & 0.4 & 1.4168 & 0.3944 & 1.57 & 100 & 1.126 & 0.4 & 1.1149 & 0.3911 & 0.99 \\
\hline
\end{tabular}

$\mathrm{PR}=1$, Central well, $x_{\mathrm{eD}} / y_{\mathrm{eD}}=1, r_{\mathrm{wD}}=10^{-4}$

\begin{tabular}{|c|c|c|c|c|c|c|c|c|c|c|c|}
\hline \multirow[t]{2}{*}{$L_{\mathrm{D}}$} & \multicolumn{2}{|c|}{ Mutalik et al. (1988) } & \multicolumn{2}{|c|}{ This study } & \multirow[t]{2}{*}{$C_{A} \% \mathrm{Err}$} & \multirow[t]{2}{*}{$L_{\mathrm{D}}$} & \multicolumn{2}{|c|}{ Mutalik et al. (1988) } & \multicolumn{2}{|c|}{ This study } & \multirow[t]{2}{*}{$C_{A} \% \mathrm{Err}$} \\
\hline & $C_{A}$ & $\left(T_{\mathrm{DA}}\right)_{\mathrm{PSS}}$ & $C_{A}$ & $\left(T_{\mathrm{DA}}\right)_{\mathrm{PSS}}$ & & & $C_{A}$ & $\left(T_{\mathrm{DA}}\right)_{\mathrm{PSS}}$ & $C_{A}$ & $\left(T_{\mathrm{DA}}\right)_{\mathrm{PSS}}$ & \\
\hline 1 & 0.00085 & 0.4 & 0.0005 & 0.3924 & 71.72 & 1 & 0.0044 & 0.6 & 0.0009 & 0.7396 & 396.05 \\
\hline 5 & 0.2773 & 0.4 & 0.2489 & 0.3924 & 11.41 & 5 & 0.5869 & 0.6 & 0.4254 & 0.7396 & 37.96 \\
\hline 10 & 0.501 & 0.4 & 0.4747 & 0.3924 & 5.55 & 10 & 0.9531 & 0.6 & 0.8115 & 0.7396 & 17.45 \\
\hline 20 & 0.6506 & 0.4 & 0.6332 & 0.3924 & 2.75 & 20 & 1.1734 & 0.6 & 1.0826 & 0.7396 & 8.39 \\
\hline 50 & 0.7435 & 0.4 & 0.7354 & 0.3924 & 1.10 & 50 & 1.2986 & 0.6 & 1.2574 & 0.7396 & 3.28 \\
\hline 100 & 0.771 & 0.4 & 0.7666 & 0.3924 & 0.58 & 100 & 1.3322 & 0.6 & 1.3108 & 0.7396 & 1.64 \\
\hline \multicolumn{6}{|c|}{$\mathrm{PR}=0.4$, Central well, $x_{\mathrm{eD}} / y_{\mathrm{eD}}=2, r_{\mathrm{wD}}=10^{-4}$} & \multicolumn{6}{|c|}{$\mathrm{PR}=0.6$, Central well, $x_{\mathrm{eD}} / y_{\mathrm{eD}}=2, r_{\mathrm{wD}}=10^{-4}$} \\
\hline \multirow[t]{2}{*}{$L_{\mathrm{D}}$} & \multicolumn{2}{|c|}{ Mutalik et al. (1988) } & \multicolumn{2}{|c|}{ This study } & \multirow[t]{2}{*}{$C_{A} \% \mathrm{Err}$} & \multirow[t]{2}{*}{$L_{\mathrm{D}}$} & \multicolumn{2}{|c|}{ Mutalik et al. (1988) } & \multicolumn{2}{|c|}{ This study } & $C_{A} \% \mathrm{Err}$ \\
\hline & $C_{A}$ & $\left(T_{\mathrm{DA}}\right)_{\mathrm{PSS}}$ & $C_{A}$ & $\left(T_{\mathrm{DA}}\right)_{\mathrm{PSS}}$ & & & $C_{A}$ & $\left(T_{\mathrm{DA}}\right)_{\mathrm{PSS}}$ & $C_{A}$ & $\left(T_{\mathrm{DA}}\right)_{\mathrm{PSS}}$ & \\
\hline 1 & 0.0033 & 0.6 & 0.0009 & 0.708 & 278.01 & 1 & 0.0013 & 0.6 & 0.0008 & 0.6296 & 63.11 \\
\hline 5 & 0.544 & 0.6 & 0.4180 & 0.708 & 30.14 & 5 & 0.423 & 0.6 & 0.3817 & 0.6296 & 10.83 \\
\hline 10 & 0.9095 & 0.6 & 0.7972 & 0.708 & 14.08 & 10 & 0.7664 & 0.6 & 0.7279 & 0.6296 & 5.29 \\
\hline 20 & 1.1359 & 0.6 & 1.0635 & 0.708 & 6.81 & 20 & 0.9963 & 0.6 & 0.9710 & 0.6296 & 2.61 \\
\hline 50 & 1.2686 & 0.6 & 1.2351 & 0.708 & 2.71 & 50 & 1.1394 & 0.6 & 1.1277 & 0.6296 & 1.04 \\
\hline 100 & 1.3046 & 0.6 & 1.2875 & 0.708 & 1.33 & 100 & 1.1817 & 0.6 & 1.1755 & 0.6296 & 0.52 \\
\hline \multicolumn{6}{|c|}{$\mathrm{PR}=0.8$, Central well, $x_{\mathrm{eD}} / y_{\mathrm{eD}}=2, r_{\mathrm{wD}}=10^{-4}$} & \multicolumn{6}{|c|}{$\mathrm{PR}=1$, Central well, $\mathrm{x}_{\mathrm{eD}} / y_{\mathrm{eD}}=2, r_{\mathrm{wD}}=10^{-4}$} \\
\hline \multirow[t]{2}{*}{$L_{\mathrm{D}}$} & \multicolumn{2}{|c|}{ Mutalik et al. (1988) } & \multicolumn{2}{|c|}{ This study } & \multirow[t]{2}{*}{$C_{A} \% \mathrm{Err}$} & \multirow[t]{2}{*}{$L_{\mathrm{D}}$} & \multicolumn{2}{|c|}{ Mutalik et al. (1988) } & \multicolumn{2}{|c|}{ This study } & $C_{A} \% \mathrm{Err}$ \\
\hline & $C_{A}$ & $\left(T_{\mathrm{DA}}\right)_{\mathrm{PSS}}$ & $C_{A}$ & $\left(T_{\mathrm{DA}}\right)_{\mathrm{PSS}}$ & & & $C_{A}$ & $\left(T_{\mathrm{DA}}\right)_{\mathrm{PSS}}$ & $C_{A}$ & $\left(T_{\mathrm{DA}}\right)_{\mathrm{PSS}}$ & \\
\hline 1 & 0.00061 & 0.6 & 0.0006 & 0.6077 & -5.13 & 1 & 0.00025 & 0.2 & 0.0004 & 0.2138 & -39.90 \\
\hline 5 & 0.3051 & 0.6 & 0.3087 & 0.6077 & -1.15 & 5 & 0.19 & 0.2 & 0.2101 & 0.2046 & -9.56 \\
\hline 10 & 0.58525 & 0.6 & 0.5887 & 0.6077 & -0.58 & 10 & 0.381 & 0.2 & 0.4006 & 0.2046 & -4.90 \\
\hline 20 & 0.7825 & 0.6 & 0.7852 & 0.6077 & -0.35 & 20 & 0.5212 & 0.2 & 0.5344 & 0.2046 & -2.48 \\
\hline 50 & 0.9109 & 0.6 & 0.9120 & 0.6077 & -0.12 & 50 & 0.6145 & 0.2 & 0.6207 & 0.2046 & -1.00 \\
\hline 100 & 0.95 & 0.6 & 0.9507 & 0.6077 & -0.07 & 100 & 0.6438 & 0.2 & 0.6470 & 0.2046 & -0.50 \\
\hline
\end{tabular}


Table 4 (continued)

$\mathrm{PR}=0.2$, Central well, $x_{\mathrm{eD}} / y_{\mathrm{eD}}=5, r_{\mathrm{wD}}=10^{-4}$

\begin{tabular}{|c|c|c|c|c|c|c|c|c|c|c|c|}
\hline \multirow[t]{2}{*}{$L_{\mathrm{D}}$} & \multicolumn{2}{|c|}{ Mutalik et al. (1988) } & \multicolumn{2}{|c|}{ This study } & \multirow[t]{2}{*}{$C_{A} \% \mathrm{Err}$} & \multirow[t]{2}{*}{$L_{\mathrm{D}}$} & \multicolumn{2}{|c|}{ Mutalik et al. (1988) } & \multicolumn{2}{|c|}{ This study } & \multirow[t]{2}{*}{$C_{A} \%$ Err } \\
\hline & $C_{A}$ & $\left(T_{\mathrm{DA}}\right)_{\mathrm{PSS}}$ & $C_{A}$ & $\left(T_{\mathrm{DA}}\right)_{\mathrm{PSS}}$ & & & $C_{A}$ & $\left(T_{\mathrm{DA}}\right)_{\mathrm{PSS}}$ & $C_{A}$ & $\left(T_{\mathrm{DA}}\right)_{\mathrm{PSS}}$ & \\
\hline 1 & 0.0002 & 2 & 0.0001 & 2.029 & 44.93 & 1 & 0.0003 & 2 & 0.0003 & 1.957 & 19.52 \\
\hline 5 & 0.0859 & 2 & 0.0658 & 2.029 & 30.49 & 5 & 0.149 & 2 & 0.1205 & 1.957 & 23.66 \\
\hline 10 & 0.1606 & 2 & 0.1255 & 2.029 & 27.93 & 10 & 0.285 & 2 & 0.2298 & 1.957 & 24.03 \\
\hline 20 & 0.212 & 2 & 0.1675 & 2.029 & 26.60 & 20 & 0.3822 & 2 & 0.3065 & 1.957 & 24.69 \\
\hline 50 & 0.2442 & 2 & 0.1945 & 2.029 & 25.56 & 50 & 0.4446 & 2 & 0.3560 & 1.957 & 24.89 \\
\hline 100 & 0.2503 & 2 & 0.2027 & 2.029 & 23.46 & 100 & 0.4636 & 2 & 0.3711 & 1.957 & 24.93 \\
\hline \multicolumn{6}{|c|}{$\mathrm{PR}=0.6$, Central well, $x_{\mathrm{eD}} / y_{\mathrm{eD}}=5, r_{\mathrm{wD}}=10^{-4}$} & \multicolumn{6}{|c|}{$\mathrm{PR}=0.8$, Central well, $x_{\mathrm{eD}} / y_{\mathrm{eD}}=5, r_{\mathrm{wD}}=10^{-4}$} \\
\hline \multirow[t]{2}{*}{$L_{\mathrm{D}}$} & \multicolumn{2}{|c|}{ Mutalik et al. (1988) } & \multicolumn{2}{|c|}{ This study } & \multirow[t]{2}{*}{$C_{A} \%$ Err } & \multirow[t]{2}{*}{$L_{\mathrm{D}}$} & \multicolumn{2}{|c|}{ Mutalik et al. (1988) } & \multicolumn{2}{|c|}{ This study } & \multirow[t]{2}{*}{$C_{A} \% \mathrm{Err}$} \\
\hline & $C_{A}$ & $\left(T_{\mathrm{DA}}\right)_{\mathrm{PSS}}$ & $C_{A}$ & $\left(T_{\mathrm{DA}}\right)_{\mathrm{PSS}}$ & & & $C_{A}$ & $\left(T_{\mathrm{DA}}\right)_{\mathrm{PSS}}$ & $C_{A}$ & $\left(T_{\mathrm{DA}}\right)_{\mathrm{PSS}}$ & \\
\hline 1 & 0.00019 & 2 & 0.0004 & 1.75 & -47.51 & 1 & 0.0003 & 2 & 0.0003 & 1.703 & -13.29 \\
\hline 5 & 0.1869 & 2 & 0.1777 & 1.75 & 5.19 & 5 & 0.2111 & 2 & 0.1789 & 1.703 & 17.97 \\
\hline 10 & 0.3876 & 2 & 0.3389 & 1.75 & 14.39 & 10 & 0.4144 & 2 & 0.3413 & 1.703 & 21.43 \\
\hline 20 & 0.5412 & 2 & 0.4520 & 1.75 & 19.73 & 20 & 0.5609 & 2 & 0.4552 & 1.703 & 23.21 \\
\hline 50 & 0.645 & 2 & 0.5250 & 1.75 & 22.86 & 50 & 0.6571 & 2 & 0.5287 & 1.703 & 24.28 \\
\hline 100 & 0.6782 & 2 & 0.5472 & 1.75 & 23.93 & 100 & 0.687 & 2 & 0.5511 & 1.703 & 24.65 \\
\hline \multicolumn{12}{|c|}{$\mathrm{PR}=1$, Central well, $x_{\mathrm{eD}} / y_{\mathrm{eD}}=5, r_{\mathrm{wD}}=10^{-4}$} \\
\hline \multirow[t]{2}{*}{$L_{\mathrm{D}}$} & \multicolumn{2}{|c|}{ Mutalik et al. (1988) } & \multicolumn{2}{|c|}{ This study } & \multirow[t]{2}{*}{$C_{A} \%$ Err } & & & & & & \\
\hline & $C_{A}$ & $\left(T_{\mathrm{DA}}\right)_{\mathrm{PSS}}$ & $C_{A}$ & $\left(T_{\mathrm{DA}}\right)_{\mathrm{PSS}}$ & & & & & & & \\
\hline 1 & 0.00011 & 0.4 & 0.0002 & 0.4832 & -42.41 & & & & & & \\
\hline 5 & 0.1241 & 0.6 & 0.1150 & 0.07477 & 7.87 & & & & & & \\
\hline 10 & 0.2548 & 0.6 & 0.2194 & 0.07477 & 16.13 & & & & & & \\
\hline 20 & 0.3527 & 0.6 & 0.2927 & 0.07477 & 20.50 & & & & & & \\
\hline 50 & 0.4187 & 0.6 & 0.3399 & 0.07477 & 23.17 & & & & & & \\
\hline 100 & 0.4397 & 0.6 & 0.3543 & 0.07477 & 24.09 & & & & & & \\
\hline
\end{tabular}
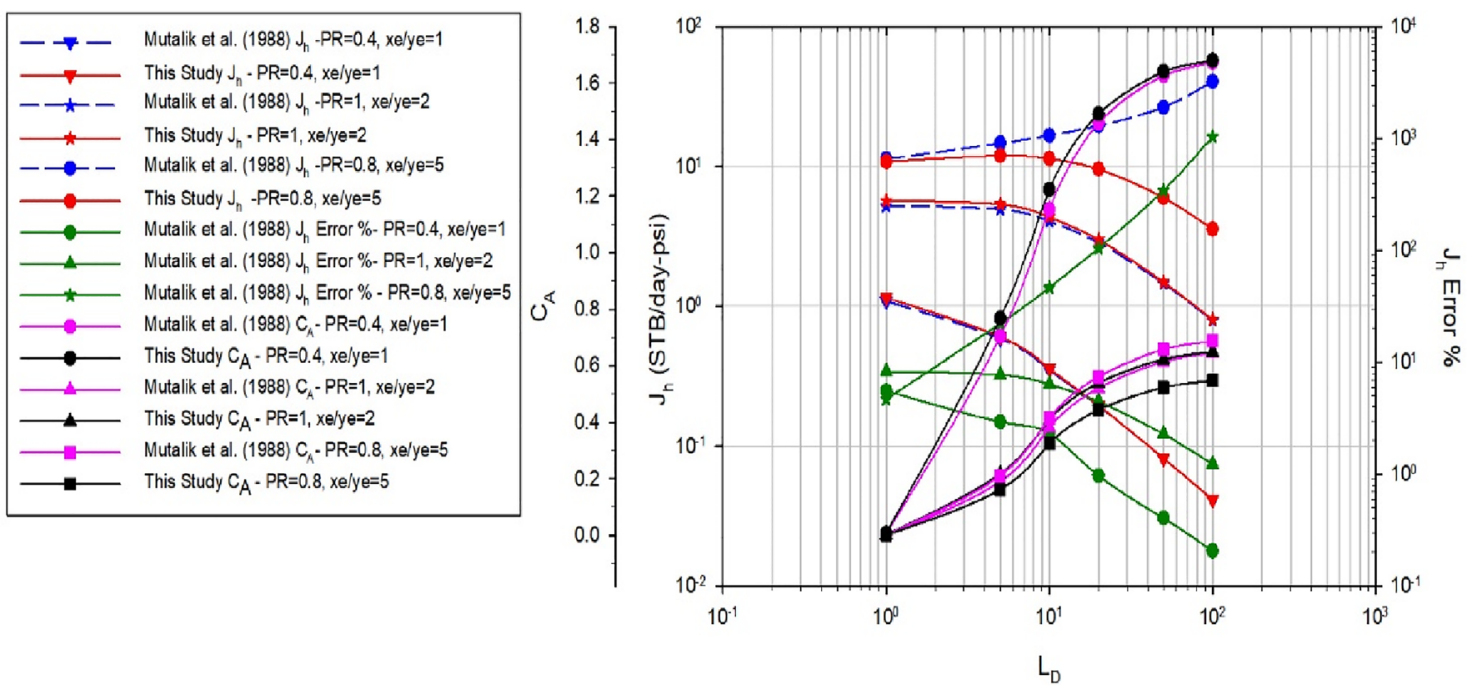

Fig. 3 The $J_{\mathrm{h}}$ comparison by using the reported $C_{A}$ tables and this study $C_{A}$ tables (variable $r_{\mathrm{wD}}$ ) 


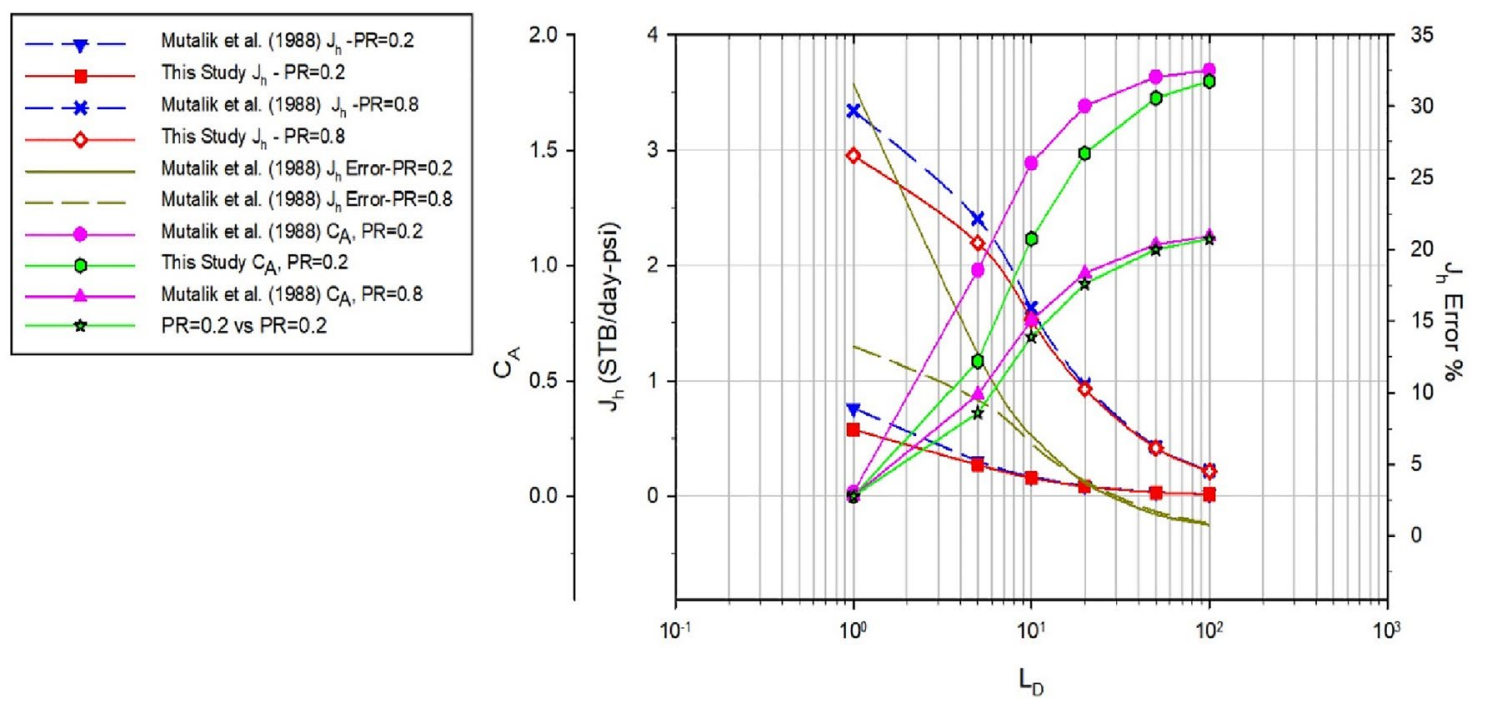

Fig. 4 The $J_{\mathrm{h}}$ comparison by using the reported $C_{A}$ tables and this study $C_{A}$ tables (constant $r_{\mathrm{wD}}=10^{-4}$ )

Fig. 5 Effect of FTLC $=\left(0-10^{-}\right.$ $\left.{ }^{9}\right)$ and $\left(0-10^{-5}\right)$ on the $C_{A}$ accuracy

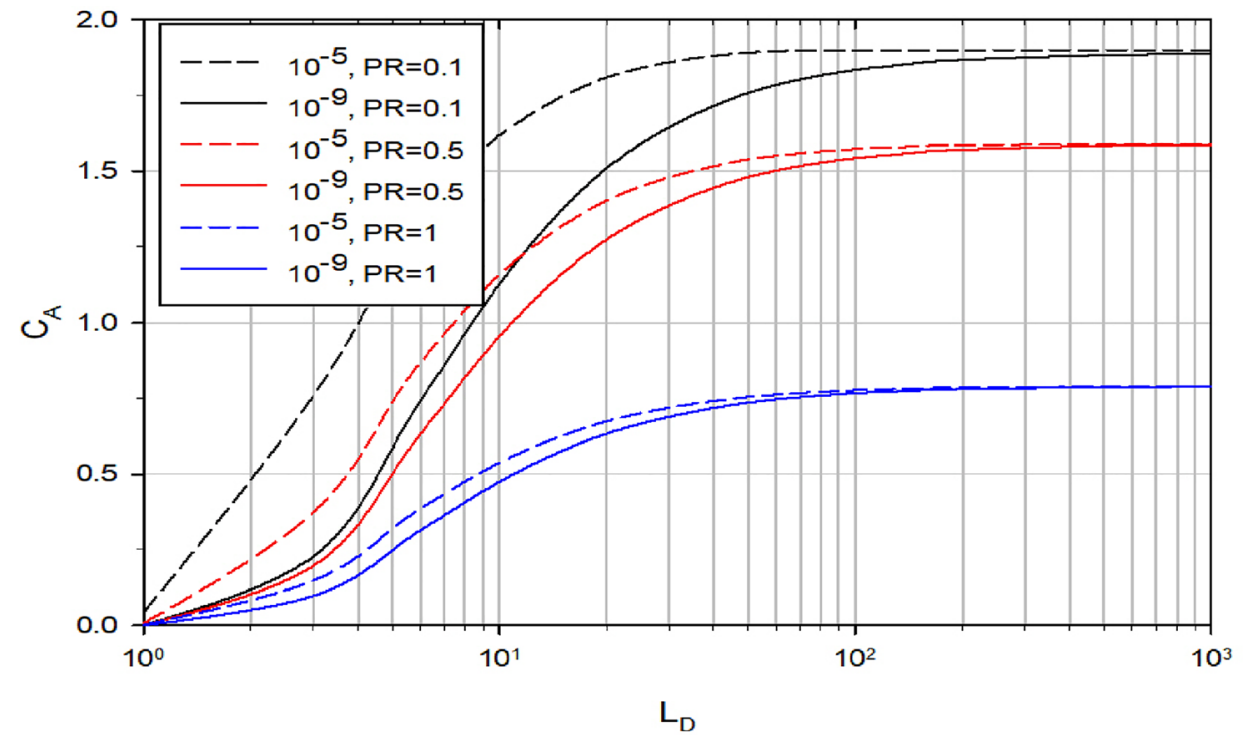

\section{Conclusions}

1. The PTM was improved to GPTM and verified by converting several dimensional parameters to dimensionless forms.

2. An efficient algorithm was developed, and accurate $C_{A}$ and $J_{\mathrm{h}}$ were obtained for any well and reservoir configuration.

3. The accuracy of the reported $C_{A}$ tables was quantified, and the consequences were determined when they were used to estimate $J_{\mathrm{h}}$.
4. New $C_{A}$ tables and their $\left(T_{\mathrm{DA}}\right)_{\mathrm{PSS}}$ tables were generated for a wider range of well and reservoir configurations. The tables are provided in the Supplementary Material.

5. Because $C_{A}$ depends on the all-configuration parameters, unlimited tables of $C_{\mathrm{A}}$ can be generated; therefore, the MATLAB code was provided.

6. Although horizontal wells usually have been drilled with high $\mathrm{L}_{\mathrm{D}}$ industrially (i.e., $L_{\mathrm{D}}>10$ ), it is still a significant error in $J_{\mathrm{h}}$ by $(<7 \%)$ that has been determined when using the reported $C_{A}$ of PTM for $\left(x_{e} / y_{e}\right)=(1)$ and (2) in the both assumed input data, while for $\left(x_{e} / y_{e}=5\right)$, a significant error in $J_{\mathrm{h}}$ starts from $(46.43 \%)$ to $(1037 \%)$ for $L_{\mathrm{D}}=(10)$ to (100), respectively, in the first assumed 
Fig. 6 The effect of OCWL in the $Z$-direction on $C_{A}$

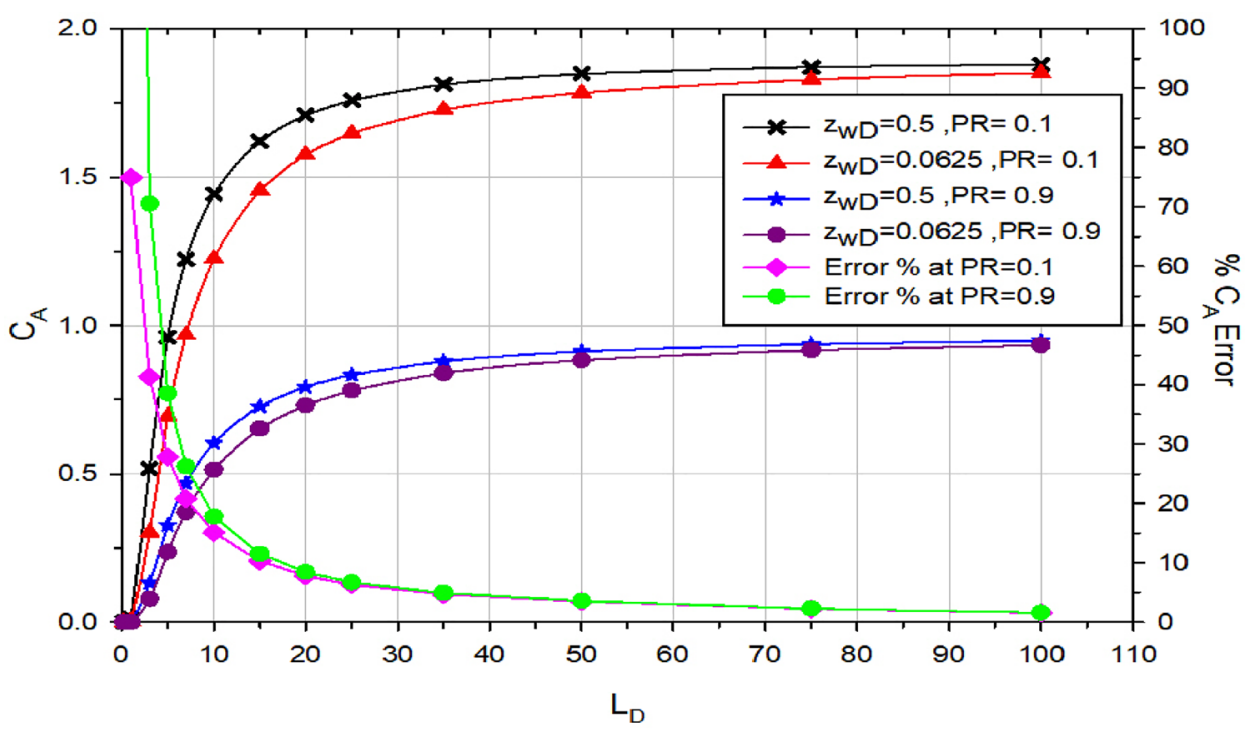

Table 5 The effect of $r_{\mathrm{wD}}$ on $C_{A}$

\begin{tabular}{|c|c|c|c|c|c|c|c|c|c|c|c|}
\hline \multicolumn{6}{|c|}{$\mathrm{PR}=0.1$, Central well, $x_{\mathrm{e}} / y_{\mathrm{e}}=1$} & \multicolumn{6}{|c|}{$\mathrm{PR}=1$, Central well, $x_{\mathrm{e}} / y_{\mathrm{e}}=1$} \\
\hline \multirow{2}{*}{$\begin{array}{l}r_{\mathrm{wD}} \\
L_{\mathrm{D}}\end{array}$} & \multicolumn{4}{|l|}{$C_{A}$} & \multirow[t]{2}{*}{$\left(T_{\mathrm{DA}}\right)_{\mathrm{PSS}}$} & \multirow[t]{2}{*}{$r_{\mathrm{wD}}$} & \multicolumn{4}{|l|}{$C_{A}$} & \multirow[t]{2}{*}{$\left(T_{\mathrm{DA}}\right)_{\mathrm{PSS}}$} \\
\hline & $5 \times 10^{-5}$ & $1 \times 10^{-4}$ & $5 \times 10^{-4}$ & $1 \times 10^{-3}$ & & & $5 \times 10^{-5}$ & $1 \times 10^{-4}$ & $5 \times 10^{-4}$ & $1 \times 10^{-3}$ & \\
\hline 1 & 0.000598 & 0.001146 & 0.006227 & 0.012452 & 0.4091 & 1 & 0.000248 & 0.000495 & 0.002476 & 0.004952 & 0.3924 \\
\hline 3 & 0.182649 & 0.226932 & 0.398949 & 0.502599 & 0.4091 & 3 & 0.077276 & 0.097352 & 0.16647 & 0.20974 & 0.3924 \\
\hline 5 & 0.514803 & 0.58642 & 0.822663 & 0.944943 & 0.4091 & 5 & 0.216684 & 0.248891 & 0.343403 & 0.394468 & 0.3924 \\
\hline 7 & 0.782982 & 0.859325 & 1.094378 & 1.208252 & 0.4091 & 7 & 0.328789 & 0.362998 & 0.456834 & 0.50439 & 0.3924 \\
\hline 10 & 1.056593 & 1.127695 & 1.335671 & 1.431512 & 0.4091 & 10 & 0.442901 & 0.474676 & 0.557565 & 0.597591 & 0.3924 \\
\hline 15 & 1.31725 & 1.375702 & 1.540035 & 1.612867 & 0.4091 & 15 & 0.551404 & 0.577472 & 0.642882 & 0.673298 & 0.3924 \\
\hline 20 & 1.462146 & 1.510542 & 1.643952 & 1.701941 & 0.4091 & 20 & 0.611638 & 0.633198 & 0.686265 & 0.710482 & 0.3924 \\
\hline 25 & 1.552613 & 1.593591 & 1.705232 & 1.753204 & 0.4091 & 25 & 0.649214 & 0.667458 & 0.711848 & 0.731882 & 0.3924 \\
\hline 35 & 1.657668 & 1.688803 & 1.772501 & 1.808014 & 0.4091 & 35 & 0.692815 & 0.706668 & 0.739932 & 0.754763 & 0.3924 \\
\hline 50 & 1.735952 & 1.758712 & 1.8193 & 1.844797 & 0.4091 & 50 & 0.725277 & 0.735398 & 0.75947 & 0.770118 & 0.3924 \\
\hline 75 & 1.794858 & 1.810513 & 1.851889 & 1.869246 & 0.4091 & 75 & 0.749682 & 0.756641 & 0.773076 & 0.780325 & 0.3924 \\
\hline 100 & 1.822908 & 1.83482 & 1.866212 & 1.879416 & 0.4091 & 100 & 0.761294 & 0.766588 & 0.779056 & 0.78457 & 0.3924 \\
\hline
\end{tabular}

input data (i.e., variable $r_{\mathrm{WD}}$ ) and expected the same in the second assumed input data (i.e., constant $\left.r_{\mathrm{WD}}\right)$.

\section{Appendix 1}

\section{Summary of pressure transient model of Mutalik et al. (1988)}

The mathematical expression of the dimensionless parameters of PTM (Eq. (3)) and the geometrical figure of PTM is given as follows:

$$
P_{\mathrm{D}} T=\frac{0.007078 k h \Delta P}{q_{w} B_{o} \mu_{o}}
$$

$$
t_{\mathrm{D}}=\frac{0.000264 k t}{\phi \mu_{0} c_{t}(L / 2)^{2}}
$$

$T_{\mathrm{DA}}=\frac{0.000264 k t}{\phi \mu_{o} c_{t} 4 x_{e} y_{e}}$

$$
x_{D}=\frac{2 x}{L}
$$




$$
\begin{aligned}
& y_{D}=\frac{2 y}{L}=r_{w D}=\frac{2 r_{w}}{L} \\
& z_{D}=\frac{z}{h} \\
& x_{\mathrm{wD}}=\frac{2 x_{w}}{L} \\
& y_{\mathrm{wD}}=\frac{2 y_{w}}{L} \\
& z_{\mathrm{wD}}=\frac{z_{w}}{h}
\end{aligned}
$$

$$
T_{\mathrm{DA}}=\frac{0.000264 k_{\mathrm{eq}} t}{\phi \mu_{o} c_{t} 4 x_{e} y_{e}}
$$

$$
x_{D}^{\prime}=\frac{2 x}{L} \sqrt{\frac{k_{\text {eq }}}{k_{x}}}
$$

$$
y_{D}{ }^{\prime}=\frac{2 y}{L} \sqrt{\frac{k_{\mathrm{eq}}}{k_{y}}}=r_{w D}{ }^{\prime}=\frac{2 r_{w}}{L} \sqrt{\frac{k_{\mathrm{eq}}}{k_{y}}}
$$

$$
L_{\mathrm{D}}^{\prime}=\frac{L}{2 h} \sqrt{\frac{k_{z}}{k_{\mathrm{eq}}}}
$$

Geometrical Figure of PTM

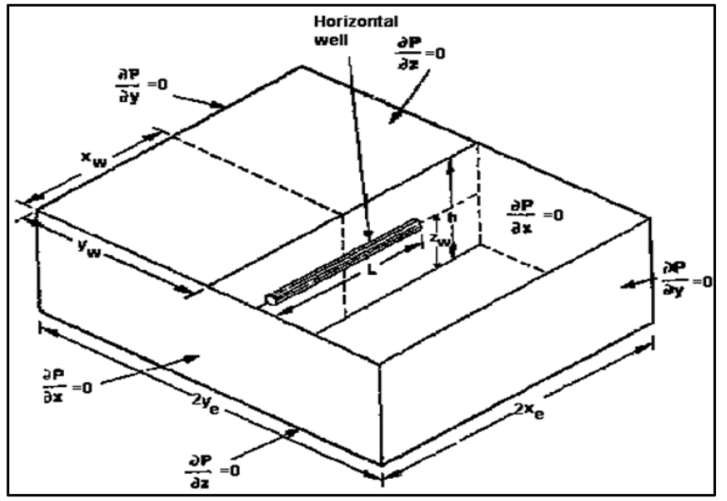

\section{Appendix 2}

$$
Z_{D}^{\prime}=\frac{z}{h}
$$

\section{The dimensionless parameters in anisotropic}

\section{reservoir}

The mathematical expression of the dimensionless parameters

$$
x_{\mathrm{WD}}^{\prime}=\frac{2 x_{W}}{L} \sqrt{\frac{k_{\mathrm{eq}}}{k_{x}}}
$$

for anisotropic reservoir by Ozkan et al. (1987), Ozkan and Raghavan (1988) and Besson (1990) in (') symbol is given as follows:

$$
y_{\mathrm{WD}}^{\prime}=L \frac{2 y_{W}}{L} \sqrt{\frac{k_{e q}}{k_{y}}}
$$

$$
\bar{k}=k_{\mathrm{eq}}=\sqrt[3]{k_{x} k_{y} k_{z}}
$$

$P_{\mathrm{D}} T^{\prime}=\frac{0.007078 k_{\mathrm{eq}} h \Delta P}{q_{w} B_{o} \mu_{o}}$

$t_{\mathrm{D}}^{\prime}=\frac{0.000264 k_{\mathrm{eq}} t}{\phi \mu_{0} c_{t}(L / 2)^{2}}$

$$
z_{\mathrm{WD}}^{\prime}=\frac{z_{W}}{h}
$$

\section{Appendix 3}

\section{The MATLAB code}


SHAPE FACTORS (CA) COMPUTATIONS

$\therefore$ PD and TDA Calculation for Rectangular Bounded Reservoir

\% THE GENERALIZED SOLUTION TO MUTALIK, P.N., GODBOLE, AND JOSHI, S.D. 'S, (1988) MODEL

clear

$\mathrm{clc}$

$\mathrm{kx}=1 ; \mathrm{ky}=1 ; \mathrm{kz}=1 ; \mathrm{kh}=\left(\mathrm{kx}^{\star} \mathrm{ky}\right) \wedge 0.5 ; \mathrm{keq}=\left(\mathrm{kx}^{\star} \mathrm{ky}^{\star} \mathrm{kz}\right)^{\wedge}(1 / 3) ;$

$\mathrm{PR}=0.2 ; \mathrm{XeD}=(1 / \mathrm{PR}) *((\mathrm{keq} / \mathrm{kX}) \wedge 0.5) ; \mathrm{YeD}=(\mathrm{XeD} / 1) *((\mathrm{keq} / \mathrm{ky}) \wedge 0.5) ; \mathrm{XWD}=1 * \mathrm{XeD} *((\mathrm{keq} / \mathrm{kx}) \wedge 0.5) ;$

$\mathrm{YWD}=1 * \mathrm{YeD} *((\mathrm{keq} / \mathrm{ky}) \wedge 0.5) ; \mathrm{LD}=1 *((\mathrm{kz} / \mathrm{keq}) \wedge 0.5) ; \mathrm{S}=0 ; \mathrm{A}=0 ;$ slope=100; slope $\mathrm{TD}=100 ;$ slopeb=10;

$\mathrm{TDA}=0 ; \quad \mathrm{PDT}=0 ; \mathrm{XD}=0.732 ; \mathrm{YD}=0.0001 *((\mathrm{keq} / \mathrm{ky}) \wedge 0.5) ; \mathrm{ZWD}=0.5 ; \mathrm{ZD}=\mathrm{ZWD} ; \mathrm{INC}=1 * 10^{\wedge}-$

9; $\mathrm{PDf}=0$, $\operatorname{diff}=0 ; \mathrm{TD}=-10 ; \mathrm{PD}=0$;

$\mathrm{T}=[0.9879925 ;-0.9879925 ; 0.9372734 ;-0.9372734 ; 0.8482066 ;-0.8482066 ; 0.7244177 ;-0.7244177 ;$

$0.5709722 ;-0.5709722 ; 0.3941513 ;-0.3941513 ; 0.2011941 ;-0.2011941 ; 0] ;$

$\mathrm{U}=[0.0307532 ; 0.0307532 ; 0.0703660 ; 0.0703660 ; 0.1071592 ; 0.1071592 ; 0.1395707 ; 0.1395707 ;$

$0.1662692 ; 0.1662692 ; 0.1861610 ; 0.1861610 ; 0.1984315 ; 0.1984315 ; 0.2025782]$;

while round $($ slopeb*10^8) $\sim=$ round $($ slope*10^8)

$T D A=I N C+T D A$;

SUM11 $=0 ; \operatorname{SUM} 22=0 ; \operatorname{SUM} 33=0 ; \operatorname{INP} 1=0 ; \operatorname{INP} 2=0 ; \operatorname{INP} 3=0 ; \mathrm{ZZ}=0 ; \mathrm{M}=0 ;$

$A=(T D A-I N C)$;

$\mathrm{M}=(\mathrm{TDA}-\mathrm{A}) / 2 ; \mathrm{C}=(\mathrm{A}+\mathrm{TDA}) / 2$;

for $L L=1: 15$

$\operatorname{TDi}=\left(\left(M^{*} \mathrm{~T}(\mathrm{LL})\right)+\mathrm{C}\right) ; \quad \operatorname{SUM} 1=0 ; \quad \operatorname{SUM} 2=0 ; \operatorname{SUM} 3=0$;

O CALCULATION OF THE FIRST SUM.TERM, X-direction

$\mathrm{RA} 1=0 ; \mathrm{RA} 2=0 ; \mathrm{RA} 3=0 ; \mathrm{PP}=0 ; \mathrm{V} 1=0 ; \mathrm{V} 2=0 ; \mathrm{V} 3=0 ； \mathrm{SUM} 1=0 ; \mathrm{NN}=0 ; \mathrm{P} 1=100$ ；

while P1 $\sim=0$

$\mathrm{NN}=\mathrm{NN}+1 ;$

$\mathrm{RA} 1=(\mathrm{NN} * \mathrm{pi}) /(2 * \mathrm{XeD}) ; \mathrm{RA} 2=(\mathrm{NN} * \mathrm{pi} * \mathrm{XWD}) /(2 * \mathrm{XeD}) ; \mathrm{RA} 3=(\mathrm{NN} * \mathrm{pi} *(\mathrm{XWD}+\mathrm{XD})) /(2 * \mathrm{XeD}) ;$

$\mathrm{PP}=\left(\left(\mathrm{NN}^{\wedge} 2\right) *(\mathrm{pi} \wedge 2) * \mathrm{YeD} * \mathrm{TDi}\right) / \mathrm{XeD}$;

$\mathrm{P} 1=1 / \exp (\mathrm{PP}) ; \mathrm{V} 1=\sin (\mathrm{RA} 1) ; \mathrm{V} 2=\cos (\mathrm{RA} 2) ; \mathrm{V} 3=\cos (\mathrm{RA} 3)$;

$\mathrm{SUM} 1=\mathrm{SUM} 1+(\mathrm{P} 1 * \mathrm{~V} 1 * \mathrm{~V} 2 * \mathrm{~V} 3 / \mathrm{NN})$;

end

$\because$ CALCULATION OF THE SECOND SUM. TERM, Y-direction

$\mathrm{RA} 11=0 ; \mathrm{RA} 22=0 ; \mathrm{PP} 2=0 ; \mathrm{V} 11=0 ; \mathrm{V} 22=0 ; \mathrm{SUM} 2=0 ; \mathrm{MM}=0 ; \mathrm{P} 2=100 ;$

while P2 $\sim=0$

$\mathrm{MM}=\mathrm{MM}+1 ;$

$\mathrm{RA} 11=\left(\mathrm{MM}^{*} \mathrm{p} i * \mathrm{YWD}\right) /(2 * \mathrm{YeD}) ; \operatorname{RA} 22=(\mathrm{MM} * \mathrm{p} i *(\mathrm{YWD}+\mathrm{YD})) /(2 * \mathrm{YeD})$

$\mathrm{PP} 2=\left(\left(\mathrm{MM}^{\wedge} 2\right) *(\mathrm{pi} \wedge 2) * \mathrm{XeD} * \mathrm{TDi}\right) / \mathrm{YeD} ;$

$\mathrm{P} 2=1 / \exp (\mathrm{PP} 2) ; \mathrm{V} 11=\mathrm{COS}(\mathrm{RA} 11) ; \mathrm{V} 22=\cos (\mathrm{RA} 22)$;

end

SUM $2=\mathrm{SUM} 2+(\mathrm{P} 2 * \mathrm{~V} 11 * \mathrm{~V} 22)$;

$\therefore$ REM*CALCULATION OF THE THIRD SUM. TERM, Z-direction

$\mathrm{RA} 111=0 ； \mathrm{RA} 222=0$ ； $\mathrm{P} 3=100$ ； $\mathrm{PP} 3=0 ； \mathrm{~V} 111=0 ； \mathrm{~V} 222=0$ ； $\mathrm{SUM} 3=0 ; \mathrm{GG}=0$ ；

while P3 $\sim=0$

$\mathrm{GG}=\mathrm{GG}+1$;

$\mathrm{RA} 111=(\mathrm{GG} * \mathrm{pi} * \mathrm{ZWD}) ; \quad \mathrm{PP} 3=\left(\mathrm{GG}^{\wedge} 2\right) *(\mathrm{pi} \wedge 2) * 4 * \mathrm{XeD} * \mathrm{YeD} *\left(\mathrm{LD}^{\wedge} 2\right) * \mathrm{TDi} ;$

$\mathrm{P} 3=1 / \exp (\mathrm{PP} 3) ; \mathrm{V} 111=(\operatorname{Cos}(\mathrm{RA} 111)) \wedge 2 ;$

SUM $3=$ SUM $3+(\mathrm{P} 3 * \mathrm{~V} 111)$;

end

$\operatorname{INP} 1=\operatorname{INP} 1+(\mathrm{U}(\mathrm{LL}) *(1+(4 * \mathrm{XeD}$ *SUM $1 / \mathrm{p} i)))$ * $(1+(2 *$ SUM 2$))$ * $(1+(2 *$ SUM 3$))$;

end

$\mathrm{PDf}=\mathrm{PDT} ; \mathrm{TD}=4 * \mathrm{XeD} * \mathrm{YeD} * \mathrm{TDA}, \mathrm{TDINC}=4 * \mathrm{XeD} * \mathrm{YeD} * \mathrm{INC}$

$\mathrm{PD}=(\mathrm{INP} 1 * \mathrm{M} * \mathrm{pi} * 2), \mathrm{PDT}=\mathrm{PDT}+\mathrm{PD}$, slopeb=slope,

$\mathrm{CA}=(2.2458 * \mathrm{XeD} * \mathrm{YeD}) *(\exp ((4 * \mathrm{p} i * \mathrm{TDA})-(2 * \mathrm{PDT}))) ;$

$\mathrm{SCA}=\log ((30.8828 / \mathrm{CA}) \wedge 0.5) ; \mathrm{slope}=(\mathrm{PDT}-\mathrm{PDf}) / \mathrm{INC} ; \operatorname{diff}=(\mathrm{PDT}-\mathrm{PDf}) ;$ slopeTD= $(\mathrm{PDT}-\mathrm{PDf}) / \mathrm{TDINC}$;

TDA,

TD,

$\mathrm{PD}$,

$\mathrm{PDT}$,

$\mathrm{CA}$,

SCA,

slopeb,

slope,

if $\operatorname{TDA}>10^{\wedge}-5$

$\operatorname{INC}=10^{\wedge}-8$;

end

if $T D A>10^{\wedge}-4$

INC $=10^{\wedge}-7$;

end

if $\operatorname{TDA}>10^{\wedge}-3$

end

INC $=10^{\wedge}-6$;

if $T D A>10^{\wedge}-2$

INC $=10^{\wedge}-5$;

end

if $\mathrm{TDA}>10^{\wedge}-1$

$\mathrm{INC}=10^{\wedge}-4$

end

if $T D A>1$

INC $=10^{\wedge}-3$;

end 
Supplementary Information The online version contains supplementary material available at https://doi.org/10.1007/s13202-02101339-3.

Funding No funding supported this study.

\section{Declarations}

Conflict of interest The authors declare no conflict of interest.

Open Access This article is licensed under a Creative Commons Attribution 4.0 International License, which permits use, sharing, adaptation, distribution and reproduction in any medium or format, as long as you give appropriate credit to the original author(s) and the source, provide a link to the Creative Commons licence, and indicate if changes were made. The images or other third party material in this article are included in the article's Creative Commons licence, unless indicated otherwise in a credit line to the material. If material is not included in the article's Creative Commons licence and your intended use is not permitted by statutory regulation or exceeds the permitted use, you will need to obtain permission directly from the copyright holder. To view a copy of this licence, visit http://creativecommons.org/licenses/by/4.0/.

\section{References}

Adesina FAS, Churchill A, Olugbenga F (2011) Modeling productivity index for long horizontal well. J Energy Resour Technol, 133(3)

Ahmadi MA, Soleimani R, Lee M, Kashiwao TB (2015) Determination of oil well production performance using artificial neural network (ANN) linked to the particle swarm optimization (PSO) tool. Petroleum 1:118-132

Bahadori A, Jamili A, Zendehboudi S (2013) Calculating pseudosteady-state horizontal oil well productivity in rectangular drainage areas using a simple method. Chem Eng Commun 200(2):222-234

Bahadori A (2012) Prediction of skin factor and pseudo-steady state horizontal wells productivity for various drainage areas. In: Presented at SPE 2012 energy conference and exhibition, Port of Spain, Trinidad. https://doi.org/10.2118/156278-MS

Besson J (1990) Performance of slanted and horizontal wells on an anisotropic medium. In: Presented at Europec 90, Hague. https:// doi.org/10.2118/20965-MS

Brown GA, Tiwari P (2010) Using DTS flow measurements below electrical submersible pumps to optimize production from depleted reservoirs by changing injection support around the well. In: Presented at SPE annual technical conference and exhibition, Florence. https://doi.org/10.2118/135130-MS

Cetkovic I, Shammari M, Sager T (2016) A methodology for multilateral wells optimization-field case study. In: Abu Dhabi international petroleum exhibition \& conference

Cho H (2003) Integrated optimization on a long horizontal well length. SPE Reserv Eval Eng 6(02):81-88

Duda JR, Salamy SP, Aminian K, Ameri S (1991) Pressure analysis of an unstimulated horizontal well with type curves. J Petrol Technol 43(08):988-993

Earlougher RCJ (1977) Advances in well test analysis. Society of Petroleum Engineers, Richardson, Texas, USA

Economides M, Deimbachor FX, Brand CW, Heinemann ZE (1991a) Comprehensive-simulation of horizontal-well performance. SPE Form Eval 6(04):418-426

Economides MJ, Naceur KB, Klem RC (1991b) Matrix stimulation method for horizontal wells. J Petrol Technol 43(07):854-861
Frick TP, Economides MJ (1993) Horizontal well damage characterization and removal. SPE Prod Facil 8(01):15-22

Gringarten AC, Ramey HJ (1973) The use of source and green's functions in solving unsteady-flow problems in reservoirs. Soc Petrol Eng J. https://doi.org/10.2118/3818-PA

Gringarten AC, Ramey HJ, Raghavan R (1974) Unsteady-state pressure distributions created by a well with a single infinite-conductivity vertical fracture. Soc Petrol Eng J. https://doi.org/10. 2118/4051-PA

Hagoort J (2009) The productivity of a well with a vertical infiniteconductivity fracture in a rectangular closed reservoir. Soc Petrol Eng J. https://doi.org/10.2118/112975-PA

Haidar A, Vafin I, Borisov G, Dzhabrailov A, Nikitin A (2008) Formation hydrofracturing experience on horizontal wells of $\mathrm{N} @ \mathrm{~N}$ NK rosneft. In: Presented at SPE 2008 Russian oil \& gas technical conference and exhibition, Moscow. https://doi.org/10.2118/ 117418-MS

Huebsch H, Moss M, Trilsbeck T, Brown G, Rogers S, Bouchard T (2008) Monitoring inflow distribution in multi-zone, velocity string gas wells using slickline deployed fiber optic distributed temperature measurements. In: Presented at SPE 2008 annual technical conference and exhibition, Denever, Colorado. https:// doi.org/10.2118/115816-MS

Jackson GT, Balhoff MT, Huh C, Delshad M (2011) CFD-based representation of non-Newtonian polymer injectivity for a horizontal well with coupled formation-wellbore hydraulics. J Petrol Sci Eng 78(1):86-95

Krawchuk P, Beshry MA, Brown GA, Brough B (2016) Predicting the flow distribution on total E\&P Canada's Joslyn Project horizontal SAGD producing wells using permanently installed fiber-optic monitoring. In: Presented at SPE 2006 annual technical conference, San Antonio, Texas. https://doi.org/10.2118/102159-MS

Leone A, Galli G, Drago A, Brown G (2015) Characterizing reservoir thermofacies by using distributed temperature sensing measurements. In: Presented at SPE annual technical conference and exhibition, Houston, Texas. https://doi.org/10.2118/175080-MS

Luo W, Tang C, Feng Y (2018) A semianalytical model for horizontalwell productivity with pressure drop along the wellbore. SPE J 23(05):1603-1614

Mutalik PN, Godbole SP, Joshi SD (1988) Effect of drainage area shapes on the productivity of horizontal wells. In: Presented at SPE 63rd annual technical conference and exhibition, Houston, Texas. https://doi.org/10.2118/18301-MS.

Ouyang L-B (2015) Assessing the needs to incorporate completion details in a petroleum eservoir simulation model. Open Petrol Eng J 8:16-28

Ozkan E, Raghavan R (1988) Some new solutions to solve problems in well test analysis: Part 1 - Analytical considerations. Paper Soc Petrol Eng 18615

Ozkan E, Raghavan R, Joshi SD (1988) Horizontal well pressure analysis. In: Presented at SPE California regional meeting, Ventura, California. https://doi.org/10.2118/16378-MS

Penmatcha VR, Arbabi S, Aziz K (1999) Effects of pressure drop in horizontal wells and optimum well length. SPE J 4(03):215-223

Pinzon ID, Davies JE, Mammadkhan F, Brown GA (2007) Monitoring production from gravel-packed sand-screen completions on BP's azeri field wells using permanently installed distributed temperature sensors. In: Presented at SPE 2007 annual technical conference and exhibition, Anaheim, California. https://doi.org/ 10.2118/110064-MS

Saavedra NF, Joshi SD (2002) Application of horizontal well technology in Colombia. J Can Petrol Technol 41(03)

Thomas LK, Todd BJ, Evans CE, Pierson RG (1998) Horizontal well IPR calculations. SPE Reserv Eval Eng 1(05):392-399 
Wood P, Simpson A, Holland B, Brown G, Rogers G, Anderson S, Balster E, Figueroa M (2010) Monitoring flow and completion integrity of a north sea subsea HPHT appraisal well during an extended well test using permanently installed fiber-optic temperature sensors. In: Presented at SPE deep water drilling and completions conference, Galveston, Texas. https://doi.org/10. 2118/137120-MS

Wu M, Luo W, Wang X (2018) A new algorithm for computation of horizontal-well pressure in Laplace domain. Adv Geo-Energy Res 2(4):393-403
Zhang L, Zheng W, Zhu G (2020) Analysis of initial productivity evaluation method for horizontal well in offshore block oilfield. Springer, Singapore, pp. 1-13

Publisher's Note Springer Nature remains neutral with regard to jurisdictional claims in published maps and institutional affiliations. 